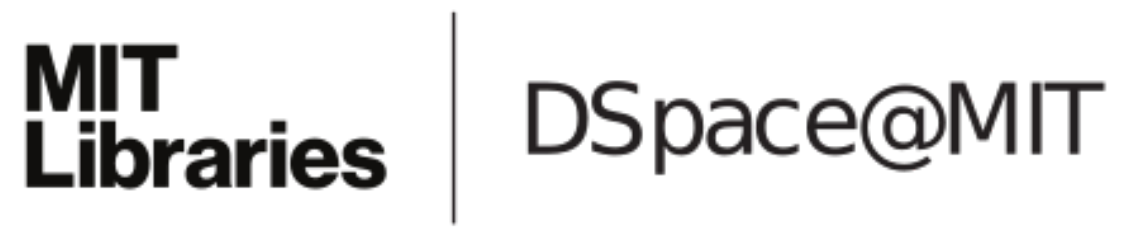

\author{
MIT Open Access Articles
}

Slow Moving Debt Crises

The MIT Faculty has made this article openly available. Please share how this access benefits you. Your story matters.

Citation: Lorenzoni, Guido and Iván Werning. "Slow Moving Debt Crises." American Economic Review 109, 9 (September 2019): 3229-3263

As Published: http://dx.doi.org/10.1257/aer.20141766

Publisher: American Economic Association

Persistent URL: https://hdl.handle.net/1721.1/126826

Version: Final published version: final published article, as it appeared in a journal, conference proceedings, or other formally published context

Terms of Use: Article is made available in accordance with the publisher's policy and may be subject to US copyright law. Please refer to the publisher's site for terms of use. 


\title{
Slow Moving Debt Crises
}

\author{
By GuIdo LORENZONI AND IVÁN WERning*
}

\begin{abstract}
We study slow moving debt crises: self-fulfilling equilibria in which high interest rates, due to the fear of a future default, lead to a gradual but faster accumulation of debt, ultimately validating investors' fear. We show that slow moving crises arise in a variety of settings, both when fiscal policy follows a given rule and when it is chosen by an optimizing government. A key assumption, in all these settings, is that the borrowing government cannot commit to issue a fixed amount of bonds in a given period. We discuss how multiplicity is avoided for low debt levels, for sufficiently responsive fiscal policy rules, and for long enough debt maturities. When the equilibrium is unique, debt dynamics are characterized by a tipping point, below which debt falls and stabilizes and above which debt and default rates grow. (JEL E43, E62, H50, H63)
\end{abstract}

In late 2010, yields on sovereign bonds of Italy, Spain, and Portugal shot up dramatically with nervous investors suddenly casting the debt sustainability of these countries into doubt. An important concern for policymakers was the possibility that higher interest rates were self-fulfilling. High interest rates, the argument goes, contribute to the rise in debt over time, eventually driving countries into insolvency, thus justifying higher interest rates in the first place. News coverage illustrates how future debt dynamics were at center stage..$^{1}$ Thomson Reuters offered a simple web application, under the title "Italian Debt Spiral," that computed the primary surplus needed to stabilize the debt-to-GDP ratio under different scenarios. ${ }^{2}$

Yields subsided in the late summer of 2012 after the European Central Bank's president, Mario Draghi, unveiled plans to purchase sovereign bonds to help sustain their market price. A view based on self-fulfilling crises was explicitly used to

\footnotetext{
* Lorenzoni: Department of Economics, Northwestern University, 2211 Campus Drive, Evanston, IL 60208 (email: guido.lorenzoni@northwestern.edu); Werning: Department of Economics, MIT, 50 Memorial Drive, Cambridge, MA 02139 (email: iwerning@mit.edu). Mark Aguiar was the coeditor for this article. For very useful comments and suggestions we thank the editor, the referees, Manuel Amador, Adrien Auclert, Fernando Broner, Hal Cole, Emmanuel Farhi, Jeffrey Frankel, Francesco Giavazzi, Pablo Kurlat, Hugo Hopenhayn, Kiminori Matsuyama, Juan Pablo Nicolini, Stavros Panageas, Matt Rognlie, Guido Sandleris, and Vivian Yue. Nicolas Caramp, Greg Howard, and Olivier Wang provided valuable research assistance.

Go to https://doi.org/10.1257/aer.20141766 to visit the article page for additional materials and author disclosure statements.

${ }^{1}$ For example, a Financial Times report on the Italian bond market cites a pessimistic observer expecting "Italian bonds to perform worse than Spanish debt this summer, as investors focus on the sustainability of Italy's debt burden," given Italy's high initial debt-to-GDP ratio. A more optimistic investor in the same report argues that Italy "can cope with elevated borrowing costs for some time particularly when shorter-dated bond yields remain anchored" and that "it's critical to bring these yields down, but there is time for Italy to establish that its policies are working" ("Investors Wary of Italy's Borrowing Test," Robin Wigglesworth, Financial Times, July 16, 2012).

${ }^{2}$ See the widget at http://graphics.thomsonreuters.com/11/07/BV_ITDBT0711_VF.html.
} 
justify such interventions during Draghi's news conference announcing the Outright Monetary Transactions (OMT) bond-purchasing program (September 6, 2012):

The assessment of the Governing Council is that we are in a situation now where you have large parts of the Euro Area in what we call a bad equilibrium, namely an equilibrium where you have self-fulfilling expectations. You may have self-fulfilling expectations that generate, that feed upon themselves, and generate adverse, very adverse scenarios. So there is a case for intervening to, in a sense, break these expectations [... ]

If this view is correct, a credible announcement to do "whatever it takes" is all it takes to rule out bad equilibria, no bond purchases need actually be carried out. Following Draghi's announcement, this is exactly how it seems to have played out: there have been no purchases by the European Central Bank (ECB) and no country has applied to the OMT program.

In this paper, we build a dynamic model that formalizes this multiple-equilibria view of debt crises. We then use this model to explore how the initial debt level, the fiscal policy regime, and the maturity of debt affect the vulnerability to such crises.

In our model, the government sells bonds to a large group of investors to finance shocks to its funding needs. Investors are risk neutral and price bonds according to their expected payoffs, forming expectations over future default probabilities. Given bond prices and fiscal policy, one can compute the path of debt. This, in turn, affects future default probabilities and, through investors' expectations, bond prices. This feedback loop between interest rates and debt accumulation opens the door to multiple equilibria.

When a crisis occurs (a switch from a good to a bad equilibrium path) bond prices jump in response to changes in future default probabilities, but the crisis can play out for some time before default actually occurs. We label this episode a slow moving crisis to distinguish it from a rollover crisis, which is essentially a run on the country's debt leading to a failed bond auction and immediate default. Both slow moving crises and rollover crises seem relevant to interpret observed turbulence in sovereign debt markets. However, the literature has mostly focused on the latter so our goal here is to highlight and study the slow moving mechanism.

Multiple equilibria arise due to a coordination problem across investors in sovereign debt markets. The precise way in which the borrower is modeled is not as crucial for multiplicity. In most of the paper, we simply take as given the behavior of the borrower, as summarized by a fixed fiscal rule that determines the primary surplus as a function of the debt level and shocks. Under a fiscal rule, default occurs mechanically when the borrower is unable to finance payments on the existing stock of debt. We also consider versions of our model where fiscal policy is endogenous, chosen by an optimizing government under discretion.

Multiple Equilibria.-Our first contribution is a characterization of bond price schedules and debt dynamics when the stochastic process for the primary surplus is given by a fiscal policy rule. This construction extends the standard analysis of debt sustainability (e.g., Bohn 1995, Hall 2014) to the case of defaultable debt. Ghosh et al. (2013) develop a related construction, but abstract from multiple equilibria. 
When all debt is in the form of short-term one-period bonds, we show that the bond price schedule is uniquely determined. This does not imply that the equilibrium path is unique because the revenue from debt issuance is not monotone in the amount of bonds issued: we call this revenue function the debt Laffer curve. Thus, for a given revenue needed by the government, there may be multiple bond prices that clear the market, at different points of the Laffer curve. We then turn to longterm debt and show that the bond price schedule is no longer uniquely determined. Future bond prices now feed back into current bond prices. The coordination problem among investors takes an intertemporal dimension. As a result, the bad equilibrium cannot be prevented by coordinating current investors.

In our model, the self-fulfilling nature of crises is typically transitory. If the economy slips down the bad path long enough, eventually debt reaches a high enough level beyond which the good path is no longer possible. Although initially triggered by self-fulfilling pessimism, the crisis itself eventually damages fundamentals. This suggests the importance of swiftly applying policies to escape or counteract a bad equilibrium, to avoid it from settling in.

Policy Rules and Maturity.-We use our model to investigate the role of the policy rule and of the debt maturity in making the economy vulnerable to self-fulfilling crises. We first show that when the fiscal rule is sufficiently active at reducing deficits when debt rises, the equilibrium is unique. The fiscal rule works to offset the negative feedback from interest rates. Higher interest rates induce a rise in debt, but if the borrower takes strong actions to repay when debt levels rise a self-fulfilling crisis is avoided.

The usual requirement for stability without default is that the slope of the rule be greater than the interest rate (see, e.g., Hall 2014). We show that the presence of default risk requires a more aggressive rule, not just because the interest rate is higher but because it responds endogenously to an increase in debt. This condition is enough to guarantee local stability of a good equilibrium. However, our analysis also uncovers an inherent limitation in these local conditions, in that they cannot be met globally at all debt levels simply because the primary surplus is bounded above by finite tax capacity; Ghosh et al. (2013) refer to this problem as "fiscal fatigue." This creates the potential for the emergence of a bad equilibrium, even if we start in a region of the state space where the fiscal rule is aggressive.

Next we show that longer debt maturities contribute toward uniqueness. A short maturity requires constant refinancing, exposing the borrower to increases in interest rates and amplifying the feedback effects; in contrast, a longer maturity mutes these forces. This mechanism is distinct from the one at play in rollover crises, where shorter maturities make repayment more costly in the event of a rollover crisis, increasing the strategic motive for default.

Tipping Points.-Our model captures the idea of a "tipping point" for debt dynamics, a notion which appears loosely in public debates on debt sustainability, but which acquires a precise form in our setting (see also Greenlaw et al. 2013). Even when the equilibrium is unique, there exists a threshold level of debt separating the good and bad paths for debt. Below this threshold, debt, interests rates, and default probabilities fall over time; above it, they rise. By implication, the dynamics 
are very sensitive to debt and other variables near the tipping point. This captures a different source of volatility, in which the equilibrium is unique, yet outcomes can be very sensitive to small changes in fundamentals.

Optimizing Government.-Our focus on fiscal rules allows us to isolate the coordination problem amongst investors. However, our results and analysis do not depend on this modeling choice and we study versions of our model with an optimizing government, that maximizes expected utility under discretion.

We use a model with government optimization to show that slow moving crisis dynamics can arise also when we endogenize the primary surplus. We also use a model with government optimization in the last section, to provide microfoundations for our approach to bond pricing. In particular, in most of the paper, we take the following approach: given the government's financing needs, debt issuances and bond prices are determined by the market to satisfy the government budget constraint. That is, the government cannot directly control the level of bond issuances. One may ask: why can the government not choose the quantity of bonds issued and select the equilibrium price? Our view is that this requires an implicit and strong commitment assumption: if the revenue of the bond issuance falls short, the government must adjust its surplus instantaneously and automatically. This seems implausible, as it requires an extremely responsive fiscal policy in the short run. Governments have limited room or desire for sharp adjustments in a such short time frame. Instead, it seems more reasonable to assume the government will issue more bonds to make up for the lower price. This is the assumption we adopt. The optimizing model of Section VI provide a formalization of this argument.

Related Literature.-Aguiar and Amador (2013) provide a recent survey of the sovereign debt literature. The main precursor to our paper is Calvo (1988), who introduced the feedback between interest rates and the debt burden in a two-period model in which the government chooses its financing needs, while debt issuances and interest rates are jointly determined on the bond market. Our main goal is to reinvigorate this approach and expand it to a dynamic setting, more appropriate for the study of slow moving crises. A dynamic setting allows us to explore the conditions for multiple equilibria with respect to debt levels, debt maturity, and fiscal policy rules. We also find that the nature of the multiplicity, coupled with stability refinements, is somewhat different in a more dynamic setting with long-term bonds. A handful of recent papers also adopt elements of the Calvo (1988) approach. Corsetti and Dedola $(2011,2013)$ investigate whether independent monetary policy is sufficient to insulate a government from confidence crises. Navarro, Nicolini, and Teles (2014) apply the same approach to a sovereign-default model with short-term debt similar to Arellano (2008), to investigate how likely sovereign borrowers are to enter the multiple equilibrium region.

Sovereign debt rollover crises were introduced by Giavazzi and Pagano (1989), Alesina et al. (1992), and Cole and Kehoe (1996). ${ }^{3}$ Cole and Kehoe (2000) provides a workhorse model for the more recent literature, including Conesa and Kehoe

\footnotetext{
${ }^{3}$ Chamon (2007) argues that the coordination problem in rollover crises can be avoided by appropriately designing the way in which bonds are underwritten and offered for purchase to investors by investment banks.
} 
(2012) and Aguiar et al. (2013). We see rollover crises and slow moving crises as complementary explanations for the turbulence in sovereign debt markets. Indeed, rollover crises are also possible in our model and slow moving crises are best thought of as less extreme versions of the same phenomena. For most of the paper we set rollover crises aside to focus on slow moving crises.

Our use of a fiscal rule in the baseline model follows the literature on debt sustainability (Bohn 1995, 2005) and the literature on the interaction of fiscal and monetary policy (e.g., Leeper 1991). Two recent papers consider what happens in models with fiscal rules when we take explicitly into account the possibility of government default. The first is $\mathrm{Bi}$ (2012), who postulates a relation between the maximum debt sustainable and the expected value of future revenues. Ghosh et al. (2013), mentioned above, is closer to our paper, as they derive the maximum debt sustainable endogenously, assuming default follows from the inability of the government to finance the current deficit at any finite interest rate. The main difference is that we consider the possibility of multiple equilibria.

\section{Model}

In this section, we show how to derive bond prices in a setup where the government follows a given fiscal rule and default occurs when the government is unable to raise enough revenue from new debt issuances to cover its current financing needs.

Consider an infinite horizon, discrete-time environment, with periods $t=0,1,2, \ldots$ Uncertainty is modeled by the exogenous state $s_{t}$, we call a sequence of states $s^{t}=\left(s_{0}, \ldots, s_{t}\right)$ a node and denote by $\operatorname{Pr}\left(s^{t}\right)$ the probability of node $s^{t}$. To simplify, we assume that all uncertainty is resolved at some finite date $T<\infty$. This assumption, which will be relaxed later, allows us to solve the model by backward induction, which is both revealing and simple, and ensures that multiplicity is not driven by an infinite horizon.

The government issues noncontingent bonds in a competitive credit market to a continuum of risk-neutral investors with discount factor $\beta=1 /(1+r)$. Bonds have geometrically decreasing coupons: a bond issued at $t$ promises to pay the sequence of coupons

$$
\kappa,(1-\delta) \kappa,(1-\delta)^{2} \kappa, \ldots
$$

where $\delta \in(0,1)$ and $\kappa>0$. We set $\kappa=\delta+r$, a normalization that makes the bond price 1 when the risk of default is zero at all future dates. This well-known specification for long-term bonds is useful because it avoids having to carry as a state variable the entire distribution of bonds of different maturities (see Hatchondo and Martinez 2009). Namely, a bond issued at $t-j$ is equivalent to $(1-\delta)^{j}$ bonds issued at $t$, so the vector of outstanding bonds can be summarized by the single state variable $b_{t}$, which represents total debt in equivalent newly issued bonds. The parameter $\delta$ controls the maturity of debt, $\delta=1$ corresponds to the case of a shortterm bond and $\delta=0$ corresponds to the case of a consol.

The government generates a sequence of primary fiscal surpluses $\left\{z_{t}\right\}$, representing total taxes collected minus total outlays on government purchases and transfers. A negative value of $z_{t}$ corresponds to a primary deficit. The primary surplus is 
determined by the state history $s^{t}$ and by the stock of debt $b_{t}$, according to the fiscal rule

$$
z_{t}=h\left(b_{t}, s^{t}\right)
$$

We assume that $h$ is weakly increasing in $b_{t}$, capturing a government that responds to a higher accumulated debt by cutting spending and/or raising taxes. Fiscal rules of this kind are commonly adopted in the literature studying debt sustainability (e.g., Bohn 2005, Ghosh et al. 2013). We also assume that the fiscal rule is bounded above, so $z_{t} \leq \bar{z}<\infty$. The presence of the upper bound $\bar{z}$ captures the maximum fiscal effort the government is able to make to repay its debt and captures what in International Monetary Fund (IMF) jargon is sometimes called "fiscal fatigue."

Absent default, the government budget constraint is

$$
z_{t}+q_{t} \cdot\left(b_{t+1}-(1-\delta) b_{t}\right)=\kappa b_{t}
$$

where $q_{t}$ is the price of a newly issued bond. Coupon payments on outstanding bonds are covered either by the primary surplus or by sales of newly issued bonds.

We assume that the government honors its debts whenever possible, so that default occurs only if the surplus and borrowing are insufficient to refinance outstanding debt. Let $\chi_{t}=1$ denote full repayment and $\chi_{t}=0$ denote default. We assume that after a default event debtors receive a recovery value $v_{t}=v\left(b_{t}, s^{t}\right) \geq 0$, which is divided equally among all bondholders and we assume that this recovery value is bounded above. Therefore, bond prices at date $t$ satisfy rational expectations if

$$
q_{t}=\beta E\left[\chi_{t+1}\left(\kappa+(1-\delta) q_{t+1}\right)+\left(1-\chi_{t+1}\right) \frac{v_{t+1}}{b_{t+1}} \mid s^{t}\right] .
$$

\section{A. Equilibrium}

To construct an equilibrium we need to find a sequence of bond price functions $Q\left(b_{t+1}, s^{t}\right)$, debt issuance functions $B\left(b_{t}, s^{t}\right)$ and repayment indicators $X\left(b_{t}, s^{t+1}\right)$ such that whenever the government budget constraint can be satisfied for one or more values of $b_{t+1}$, then $B\left(b_{t}, s^{t}\right)$ is selected among these values and whenever the government budget constraint is not satisfied for any $b_{t+1}$ default follows and $X\left(b_{t}, s^{t+1}\right)$ is set to 0 . The bond price functions must satisfy rational expectations. We now construct these functions by backward induction.

At date $T$ the process $s_{t}$ stops. We assume that from then on the surplus is constant at the level $z_{T}=h\left(b_{T}, s^{T}\right)$ and the government repays if and only if this surplus is sufficient to pay the interest on the debt $b_{T}$ forever, that is, if

$$
z_{T}=h\left(b_{T}, s^{T}\right) \geq r b_{T}
$$

At date $T$, we let the repayment function $X_{T}\left(b_{T}, s^{T}\right)$ equal 1 if this condition is met and 0 otherwise. We write the last period budget constraint as an inequality, instead of an equality, to allow larger surpluses than those needed to service the debt. $\square^{4}$

\footnotetext{
${ }^{4}$ One should hence interpret the value $z_{T}$ as the potential maximal surplus, not the actual surplus. If $z_{T}>r b_{T}$ any slack will be directed to lower taxes or higher spending.
} 
For all periods $t<T$ we proceed iteratively as follows. First, we compute the price of debt for every possible value of $b_{t+1}$, obtaining the bond price function

$$
\begin{aligned}
Q_{t}\left(b_{t+1}, s^{t}\right) \equiv \beta E\left[X_{t+1}\left(b_{t+1}, s^{t+1}\right)(\kappa\right. & \left.+(1-\delta) Q_{t+1}\left(B_{t+2}\left(b_{t+1}, s^{t+1}\right), s^{t+1}\right)\right) \\
& \left.+\left(1-X_{t+1}\left(b_{t+1}, s^{t+1}\right)\right) \frac{v\left(b_{t+1}, s^{t+1}\right)}{b_{t+1}} \mid s^{t}\right] .
\end{aligned}
$$

Recall that if default does not occur in the final period $T$ the debt becomes risk-free, so for $t=T-1$ the function $Q_{T}\left(B_{T+1}\left(b_{T}, s^{T}\right), s^{T}\right)$ on the right-hand side of $(3)$ is replaced by the value 1 .

Given the bond price function define the maximum debt revenue as follows:

$$
m_{t}\left(b_{t}, s^{t}\right) \equiv \max _{b}\left\{Q_{t}\left(b, s^{t}\right) \cdot\left(b-(1-\delta) b_{t}\right)\right\}
$$

Default can be avoided if and only if

$$
h\left(b_{t}, s^{t}\right)+m_{t}\left(b_{t}, s^{t}\right) \geq \kappa b_{t}
$$

We let the repayment function $X_{t}\left(b_{t}, s^{t}\right)$ equal 1 if this condition is met and 0 otherwise. Whenever $X_{t}\left(b_{t}, s^{t}\right)=1$ we select a $b_{t+1}$ that satisfies the government budget constraint

$$
h\left(b_{t}, s^{t}\right)+Q_{t}\left(b_{t+1}, s^{t}\right)\left(b_{t+1}-(1-\delta) b_{t}\right)=\kappa b_{t}
$$

and denote the selected value $B_{t+1}\left(b_{t}, s^{t}\right)$. The possibility that multiple values of $b_{t+1}$ solve (5) is the source of equilibrium multiplicity in this model. This possibility depends on the shape of the function $Q_{t}\left(b_{t+1}, s^{t}\right)\left(b_{t+1}-(1-\delta) b_{t}\right)$, which we call the debt Laffer curve and is analyzed in the next section.

When debt is short term, $\delta=1$, the functions $Q_{t}, m_{t}, X_{t}$ are uniquely determined as the pricing function in (3) does not depend on what value of $b_{t+1}$ is selected to solve (5) in the following period. This observation is summarized in the following result.

PROPOSITION 1: With short-term debt $(\delta=1)$ the functions $Q_{t}, m_{t}, X_{t}$ are uniquely defined and the function $m_{t}\left(b_{t}, s^{t}\right)$ does not depend on $b_{t}$.

When $\delta<1$, on the other hand, future equilibrium selection matters for current prices, so multiplicity in the future selection of $b_{t+1}$ translates into multiplicity of the functions $Q_{t}, m_{t}, X_{t}$ today.

Once we have constructed the functions $Q_{t}, m_{t}, X_{t}, B_{t+1}$ iterating backward, equilibrium paths are obtained by iterating forward on $b_{t+1}\left(s^{t}\right)=B_{t+1}\left(b_{t}\left(s^{t-1}\right), s^{t}\right)$ starting with a given level of initial debt $b_{0}$ and an initial state $s_{0}$. Evaluating $q_{t}\left(s^{t}\right)=Q_{t}\left(b_{t}\left(s^{t}\right), s^{t}\right)$ then gives the equilibrium sequence of bond prices. By including a sunspot variable in the state $s_{t}$ this construction also allows for random selection of continuation equilibria when multiplicity arises. 


\section{B. Multiplicity, Selection, and Timing Assumptions}

If, at each juncture in the backward induction, one always selects the lowest $b_{t+1}$ solving equation (5), the recursion pins down both a unique sequence $\left\{m_{t}, Q_{t}, X_{t}, B_{t+1}\right\}$ and a unique outcome $b_{t}\left(s^{t}\right)$ and $q_{t}\left(s^{t}\right)$. We then have the following result.

PROPOSITION 2: There is a unique equilibrium satisfying the requirement that $B_{t+1}\left(b_{t}, s^{t}\right)$ always equals the lowest possible solution to (5).

If, instead, we do not impose a selection criterion, multiple equilibria arise whenever (5) admits multiple solutions for some realizations of $s^{t}$ and $b_{t}$. This is the approach we follow in the rest of the paper.

We conclude this section discussing briefly alternative approaches to selection and multiplicity. The sovereign-debt literature following Eaton and Gersovitz (1981), and the subsequent quantitative literature started by Arellano (2008), make the assumption that the government chooses the quantity of bonds it auctions each period and then investors bid and determine the bond price. This timing assumption acts as a selection criterion picking a unique value of $b_{t+1}$ in each period, and thus leads to uniqueness. ${ }^{5}$ Implicit in this timing is an assumption that the government has the ability to commit to a given amount of bonds issued, both on and off the equilibrium path. However, committing to a given amount of bonds issued requires a credible commitment to cut spending or raise taxes if bond prices turn out lower than expected. In practice, the credibility of an announcement of this kind seems questionable. ${ }^{6}$

Consider a government that is running a bond auction every week. Suppose that on a given week the government has to finance a deficit of 100 million euros. It announces it will sell 10 million bonds, expecting a price of 10 euros per bond. Suppose now that the bond price turns out to be 9 euros: the government is short 10 million. Should we expect the government to immediately implement tax increases or spending cuts for 10 million, or should we expect it to run down its liquid reserves and increase bond issuances in the following weeks? We see the second form of adjustment as more plausible in the short run.

In the model presented here, in which the government follows a fiscal rule, the primary surplus is fixed at the beginning of each period (which can represent, say, a quarter). Our timing assumption is that each period the government takes as given bond prices and adjusts bond issuances to satisfy the budget constraint (5). All values of $b_{t+1}$ that solve (5) are then legitimate equilibrium outcomes.

\footnotetext{
${ }^{5}$ In finite horizon versions of the models in Eaton and Gersovitz (1981) and Arellano (2008), the backward induction argument behind Proposition 2 can be easily extended to prove uniqueness. In the infinite horizon case things are more difficult, since a backward induction argument is unavailable. Auclert and Rognlie (2014) show uniqueness in the infinite horizon case under some conditions.

${ }^{6}$ Given a non-negativity constraint on spending and an upper bound on tax revenues, one also has to worry about the very feasibility of committing to a given level of bond issuances for any realization of the price $q_{t}$ off the equilibrium path. Consider a setup with short-term debt, where the budget constraint is $q_{t} b_{t+1} \geq b_{t}-s_{t}$. Given a committed level $b_{t+1}$, if the price is low enough and the maximum achievable primary surplus is too low to fully repay $b_{t}$, then it is infeasible for the government to fulfill its commitment: either $b_{t+1}$ has to be increased, or the government has to default. The timing in Cole and Kehoe (2000), by allowing for default triggered by low bond prices, has the virtue of ensuring that payoffs are well defined for all possible strategies.
} 
In Section VI we study a game with repeated bond auctions to provide a theoretical foundation for the timing assumption above.

\section{Short-Term Debt}

In this section and the next we analyze equilibrium multiplicity by studying the properties of the debt Laffer curve. We begin with the case of short-term debt. With short-term debt $\delta=1$ and $\kappa=1+r$, so the government budget constraint is simply

$$
z_{t}+Q_{t}\left(b_{t+1}, s^{t}\right) b_{t+1}=(1+r) b_{t}
$$

and the debt Laffer curve is $Q_{t}\left(b_{t+1}, s^{t}\right) b_{t+1}$. Two examples of debt Laffer curves are represented in Figure 1. The dashed line represents the government current financing needs $(1+r) b_{t}-z_{t}$. An equilibrium is given by an intersection of the debt Laffer curve with the dashed line.

Panel A of Figure 1 shows an example with zero recovery. With zero recovery the function $Q_{t}\left(b_{t+1}, s^{t}\right) b_{t+1}$ reaches zero when $b_{t+1}$ is large enough. This follows because the value of $z_{t+1}$ is bounded above, so for $b_{t+1}$ large enough default is certain at $t+1$ and $Q_{t}\left(b_{t+1}, s^{t}\right)=0$. Of course, we also have $Q_{t}\left(b_{t+1}, s^{t}\right) b_{t+1}=0$ at $b_{t+1}=0$. This means that whenever the government has positive financing needs, $(1+r) b_{t}-z_{t}>0$, and a solution to (6) exists, there is always more than one solution, as shown in the figure. In particular, the example in panel A of Figure 1 features two solutions. In the high-debt equilibrium, the low bond price forces the government to sell more bonds to meet its financial obligations; the higher debt leads to a higher probability of default in the future, which justifies the low bond price. This two-way feedback between low bond prices and high debt makes multiple equilibria possible.

Panel B of Figure 1 shows an example with positive recovery. Now the Laffer curve converges to the recovery value for high debt. This implies that if current financing needs are positive but low enough the equilibrium is unique. In the figure we see that a sufficient reduction in the initial debt level $b_{t}$ shifts the dashed line downward, eliminating the bad equilibrium.

We summarize this discussion in the following result.

PROPOSITION 3: Consider the model with short-term debt $(\delta=1)$. With zero recovery, if there is an equilibrium for a positive value of $(1+r) b_{t}-z_{t}$, then there are always at least two equilibria. With positive recovery, if $(1+r) b_{t}-z_{t}$ is low enough the equilibrium is unique.

\section{A. Stable Equilibrium Selection}

Equilibrium points where the Laffer curve is locally decreasing are "unstable" in the Walrasian sense that a small increase in the price of bonds reduces the supply by more than the demand, creating excess demand. These equilibria are also pathological on other grounds. First, they are also unlikely to be stable with respect to most 

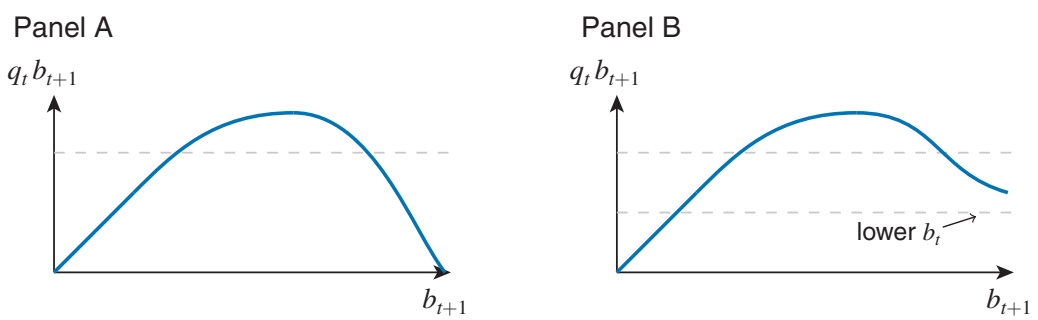

Figure 1. Debt Laffer Curve: Zero Recovery (Panel A) and Positive Recovery (Panel B)

forms of learning dynamics. Second, Frankel, Morris, and Pauzner (2003) show that global games do not select such equilibria. Third, these equilibria lead to counterintuitive comparative statics: an increase in the current debt level $b_{t}$ increases the bond price $q_{t}$, i.e., higher financing needs lower the equilibrium interest rate.

For all these reasons, from now on we discard equilibria that are unstable in this sense and only consider equilibria where the Laffer curve is locally increasing. If the Laffer curve is single-peaked, as in the examples of Figure 1, we have a unique stable equilibrium (but see the discussion below on rollover crises). Figure 2 shows a case with a multi-peaked Laffer curve which generates multiple stable equilibria.

With short-term debt, Proposition 1 implies that the bond price function is

$$
Q_{t}\left(b_{t+1}, s^{t}\right)=\operatorname{Pr}\left[h\left(b_{t+1}, s^{t+1}\right)+m_{t+1}\left(s^{t+1}\right) \geq(1+r) b_{t+1} \mid s^{t}\right]
$$

so its shape reflects the distribution of shocks and the shape of the policy function. The next proposition, proved in the online Appendix, derives a sufficient condition on the function $Q_{t}$ that implies single-peakedness of the Laffer curve.

PROPOSITION 4: If the elasticity of the price function

$$
-\frac{\partial Q_{t}\left(b_{t+1}, s^{t}\right) / \partial b_{t+1}}{Q_{t}\left(b_{t+1}, s^{t}\right)} b_{t+1}
$$

is monotone nondecreasing in $b_{t+1}$, the debt Laffer curve is single-peaked at all $t$ and there is a unique stable equilibrium.

The role of the shock distribution in generating multi-peaked debt Laffer curves and multiple equilibria is investigated in Navarro, Nicolini, and Teles (2014). They show that commonly used shock processes lead to single-peaked debt Laffer curves, but a shock process which includes a form of disaster risk can lead to bond price functions that violate the monotonicity property in Proposition 4 and produce multipeaked debt Laffer curves. In the next section, we will see that the presence of long-term debt makes it easy to generate multi-peaked Laffer curves even if the monotonicity property above is satisfied. 


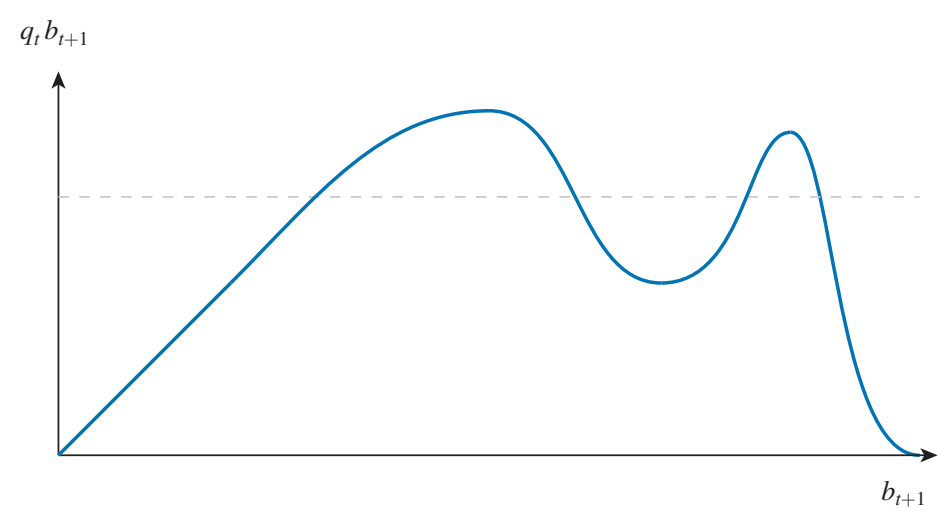

Figure 2. Multiple Stable Equilibria

\section{B. Rollover Crises}

We now consider the possibility of a different type of equilibrium. Consider panel A of Figure 1 and suppose we start immediately to the right of the bad, unstable equilibrium. At that point, there is excess bond supply so tatonnement logic says the price should fall, pushing us further to the right. This continues until we reach a level of bond issuance associated with a zero probability of repayment and a zero bond price. This suggests the presence of a third, stable equilibrium with immediate default in period $t$. We can think of this equilibrium as a rollover crisis à la Cole and Kehoe (2000): pessimistic investors force the country into immediate default and default makes future repayments impossible, justifying investors' expectations.

To allow explicitly for the possibility of a rollover crisis, we relax the assumption that default only happens when there is no issuance $b_{t+1}$ that allows the government to finance $b_{t}-z_{t}$, and introduce the possibility of default triggered by zero bond prices today. In particular, we adopt the following convention, which we state for the general case $\delta \in[0,1]$. If

$$
z_{t}+\lim _{b_{t+1} \rightarrow \infty} Q_{t}\left(b_{t+1}, s^{t}\right)\left(b_{t+1}-(1-\delta) b_{t}\right)<\kappa b_{t},
$$

we say that there is a rollover crisis equilibrium with $b_{t}=\infty$ and $q_{t}=0$ and default at $t$. With this convention, the situation depicted in panel A of Figure 1 features two stable equilibria: a low-debt equilibrium and a rollover crisis equilibrium with immediate default.

As discussed in the introduction, rollover crises are the focus of Cole and Kehoe (2000) and a large subsequent literature, so we will mostly leave them aside in this paper.

\section{Long-Term Debt}

We now turn to our benchmark case with long-term bonds. Long-term debt allows us to fully develop our idea of slow moving crises, in which higher spreads lead to a gradual increase in debt servicing costs, as the government only replaces a fraction of maturing bonds with newly issued ones. 
Introducing long-term debt is important for two other reasons. First, in most advanced economies the bulk of the debt is in the form of relatively long maturities, rather than three-month or one-year bonds (Arellano and Ramanarayanan 2012). For example, the average maturity of sovereign debt for Greece, Spain, Portugal, and Italy was in the range of 5 to 7 years over the 2000-2009 period. Second, it is widely believed that short-term borrowing exposes a sovereign borrower to debt crises and that longer maturities provides some protection. In the context of a rollover debt crisis, Cole and Kehoe (1996) find support for this view. It is of interest to see if the same is true for slow moving crises.

To analyze debt maturities longer than one period, that is, $\delta<1$, we make specific assumptions on the stochastic process for the primary surplus. In this section, we introduce these assumptions and focus the analysis on two-period and three-period versions of our model, which correspond to the last two or three periods before the resolution of uncertainty at date $T$. This allows us to get intuition on how debt maturity affects the shape of the debt Laffer curve and the possibility of multiple equilibria. In the next section, we analyze an infinite horizon version of the same model.

\section{A. A Two-Stage Process for the Primary Surplus}

The primary surplus evolves in two stages. In the first stage, the primary surplus is a deterministic function of the debt level and, with a slight abuse of notation, we have

$$
z_{t}=h\left(b_{t}\right)
$$

Each period, with Poisson probability $\lambda$ the economy switches to the second stage. After the switch occurs at some date $t$ the surplus is constant and equal to $r Z$ with $Z$ drawn from the continuous distribution $F(Z)$ with support $[0, \bar{Z}]$. The variable $Z$ is the present value of current and future surpluses. We interpret the first stage as the current policy regime and the Poisson event as a political event, like an election or the passing of a fiscal reform, after which all uncertainty about fiscal policy is resolved. At date $T$, if the Poisson event has not occurred yet, we enter the second stage with probability 1 .

The recovery value is modeled as follows. If default occurs after the Poisson event, the total recovery value is proportional to the present value of the primary surplus

$$
v_{t}=\phi(1+r) Z
$$

for some parameter $\phi \in[0,1]$. If default occurs before the Poisson event, the total recovery value is given by the expected present value of the flow $\phi \max \left\{h\left(b_{t}\right), 0\right\}$ in all periods before the Poisson event and by (7) after that.

\section{B. Maturity and Multiplicity}

We now study a two-period version of our model, by focusing our attention on the last two periods $T-1$ and $T$. 
We analyze the model proceeding backward in time, as described in Section I. When uncertainty is resolved, either after the Poisson event or at date $T$, two cases are possible. If $Z \geq b_{t}$ the government can repay at all future dates and current bondholders receive $1+r$ per bond (as the bond price is 1 ). If instead $Z<b_{t}$, each bondholder receives

$$
\phi(1+r) \frac{Z}{b_{t}}<1+r .
$$

We can then derive the bond price schedule at time $T-1$. Since agents expect uncertainty to be resolved at $T$, the bond price schedule is ${ }^{7}$

$$
Q_{T-1}\left(b_{T}\right)=\Psi\left(b_{T}\right) \equiv 1-F\left(b_{T}\right)+\phi \int_{0}^{b_{T}} \frac{Z}{b_{T}} d F(Z) .
$$

The budget constraint at $T-1$ is

$$
z_{T-1}+Q_{T-1}\left(b_{T}\right)\left(b_{T}-(1-\delta) b_{T-1}\right)=\kappa b_{T-1},
$$

and the debt Laffer curve is $Q_{T-1}\left(b_{T}\right)\left(b_{T}-(1-\delta) b_{T-1}\right)$. The crucial difference with the case of short-term debt is that now increasing $b_{T}$ reduces the value of preexisting stock of debt $(1-\delta) b_{T-1}$ and, through this dilution channel, relaxes the budget constraint. 8

We can now address the question of how maturity affects the possibility of multiple equilibria at $T-1$. To compare different maturities, let us compare economies that have the same primary surplus $z_{T-1}$, the same distribution $F$, and the same recovery parameter $\phi$, but have different values of $\delta$ and $\kappa=r+\delta$. We use the economy with short-term debt $\delta=1$ as our reference economy. For that economy, we find a good equilibrium at $b_{T}^{*}$ and $q_{T-1}^{*}=Q_{T-1}\left(b_{T}^{*}\right)$. For all other economies, we then set the initial condition $b_{T-1}$ so that the ex ante value of the existing debt,

$$
\left(\kappa+(1-\delta) q_{T-1}^{*}\right) b_{T-1}
$$

is equal to $z_{T-1}+q_{T-1}^{*} b_{T}^{*} \cdot 9$ To interpret this exercise, think that the domestic government, at the beginning of date $T-1$, before any new debt is issued, makes a take-it-or-leave-it offer to the initial bondholders, to swap all their bonds with bonds of a different maturity $\delta$. To make the bondholders indifferent the government has to offer bonds that have the same expected value. The swap is made assuming bondholders expect the good equilibrium to be played, and we then ask how the maturity swap affects the possibility of other equilibria.

Consider an economy with the following parameters:

$$
\beta=0.95, \quad \phi=0.7, \quad z_{T-1}=-0.3, \quad \log Z \sim N(0.4,0.07) .
$$

\footnotetext{
${ }^{7}$ Notice that here $Q_{T-1}$ does not depend on $s^{T-1}$ so we omit it from the notation.

${ }^{8}$ Hatchondo, Martinez, and Sosa-Padilla (2016) discuss the role of the debt dilution problem in sovereign debt models.

${ }^{9}$ The good equilibrium values of $b_{T}^{*}$ and $q_{T-1}^{*}$ can be set to the same value in all these economies, because at date $T$ the bondholders' payoff conditional on $b_{T}^{*}$ are independent of $\delta$ and $\kappa$, as can be seen from (8).
} 


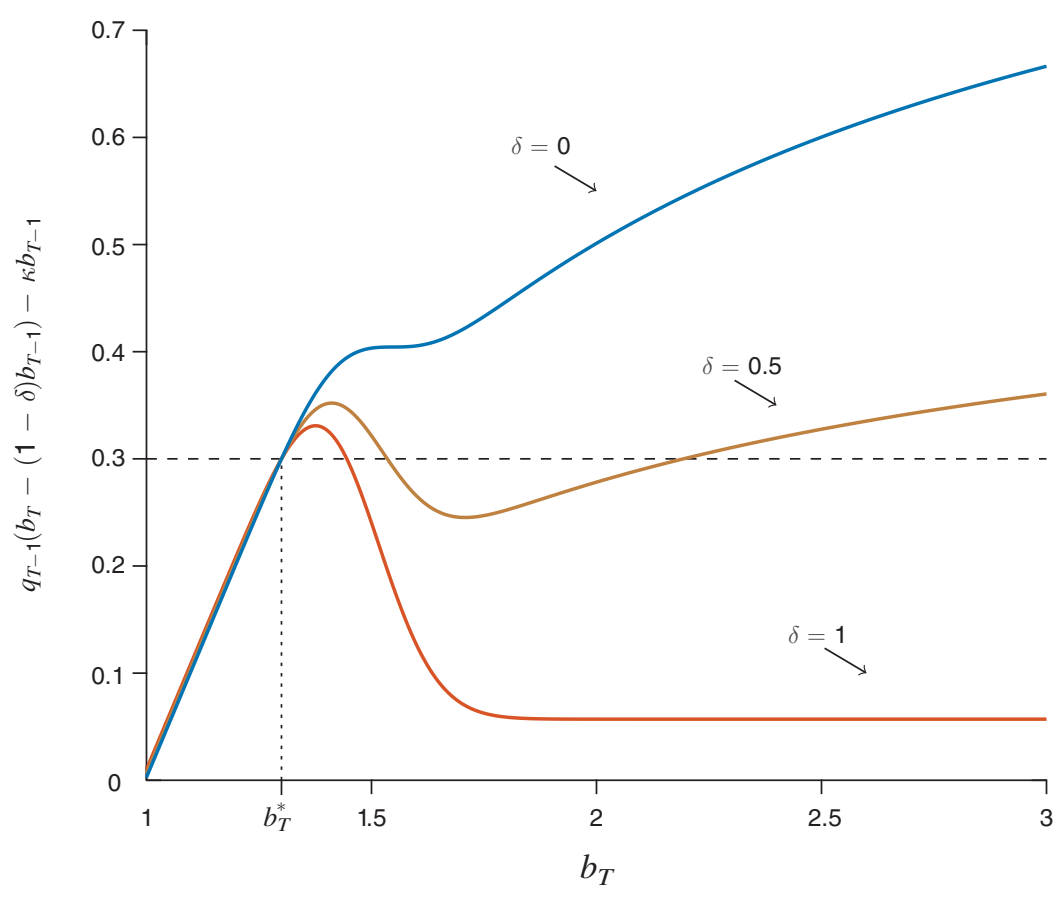

Figure 3. Maturity and Multiplicity

Figure 3 shows the debt Laffer curves in three cases: the extreme cases $\delta=1$ (one-period debt) and $\delta=0$ (consol), and the intermediate case $\delta=0.5$. The initial debt levels are chosen so that in the good equilibrium $b_{T}=b_{T}^{*}=1.3$. For ease of comparison, we plot the debt Laffer curve minus the current coupon payment $\kappa b_{T-1}$. The dashed black line corresponds to the constant primary deficit $-z_{T-1}$.

By construction, all Laffer curves cross the dashed black line at the same value $b_{T}^{*}$, the good equilibrium. However, as $\delta$ gets lower, i.e., as debt maturity gets longer, the Laffer curve shifts upward for all $b_{T}>b_{T}^{*}$ and the distance between Laffer curves of different maturity is increasing in $b_{T}$. This is a general result, proved in the next lemma, and is the result of the debt-dilution force mentioned above: with longer debt the reduction in $q_{T-1}$ due to increasing $b_{T}$, devalues the claims held by old bondholders and allows the government to raise more revenue from new debt issuances. The proof of the lemma is in the online Appendix.

LEMMA 1: Consider two economies with the same distribution $F$ and the same primary surplus $z_{T-1}$ at $T-1$. The two economies have different debt maturities $\delta$ and $\delta^{\prime}$, with $\delta^{\prime}<\delta$, and initial stocks of debt $b_{T-1}$ and $b_{T-1}^{\prime}$ that satisfy

$$
\left(r+\delta+(1-\delta) Q_{T-1}\left(b_{T}^{*}\right)\right) b_{T-1}=\left(r+\delta^{\prime}+\left(1-\delta^{\prime}\right) Q_{T-1}\left(b_{T}^{*}\right)\right) b_{T-1}^{\prime},
$$

and both have an equilibrium at $b_{T}^{*}$. The distance between the Laffer curves of the two economies,

$$
Q_{T-1}\left(b_{T}\right)\left(b_{T}-\left(1-\delta^{\prime}\right) b_{T-1}^{\prime}\right)-Q_{T-1}\left(b_{T}\right)\left(b_{T}-(1-\delta) b_{T-1}\right),
$$

is weakly increasing in $b_{T}$. 
How this result affects equilibrium multiplicity depends, in general, on the shape of the Laffer curve. Figure 3 shows how maturity affects multiplicity in our example. With short-term debt, $\delta=1$, we have a unique stable equilibrium in which the government is able to finance the primary deficit $-z_{T-1}$, but we also have a rollover crisis equilibrium as discussed in Section IIB. In the intermediate case $\delta=0.5$, we have two stable equilibria in which the government is able to finance the primary deficit $-z_{T-1}$ and no rollover crisis. ${ }^{10}$ Finally, with a consol we have a unique equilibrium at $b_{T}^{*}$ and no rollover crisis. It is possible to show that in our example, as we decrease $\delta$ continuously from 1 to 0 , we move from the first case to the second, and finally to the third. That is, the effect of longer maturity in our example is, first, to eliminate the rollover crisis and turn it into a confidence crisis with low bond prices but no immediate default, ${ }^{11}$ and next, to completely eliminate multiplicity and only leave the good equilibrium.

The possibility of multiple stable equilibria for intermediate values of $\delta$ is related to the presence of dilution. As $b_{T}$ increases three forces are at work: the stock of debt increases, the price of debt decreases reducing the value of the new stock of bonds $b_{T}$, the price of debt decreases reducing the value of the old stock of bonds $(1-\delta) b_{T-1}$. The first and the third effect increase debt revenue, the second decreases it. In the examples shown with $\delta=0.5$, the Laffer curve is initially increasing because of the first effect, as we are in a region in which the price is relatively unresponsive to $b_{T}$. Then the Laffer curve decreases as we near the mode of the distribution $Z$ and the slope of the function $Q_{T-1}\left(b_{T}\right)$ is steeper. Finally, we reach a region in which $Q_{T-1}\left(b_{T}\right) b_{T}$ flattens at the recovery value. In this region however, the dilution force is still present and makes the Laffer curve increasing again. We do not have a general analytical result, but numerical experiments suggest that this is a common pattern and inverse S-shaped Laffer curves as in Figure 3 tend to arise with $\delta<1$.

In the next section, we explore the relation between maturity and multiplicity in a richer dynamic version of the model, but the qualitative implications will be similar.

\section{Back to the Bond Price Function}

We now turn to a three-period version of the model, by going back to period $T-2$ and providing a complete characterization of the bond pricing function $Q_{T-2}\left(b_{T-1}\right)$. The following construction allows us to explore the properties of this function independently of the equilibrium selection criterion used at $T-1$ (if multiplicity is present).

\footnotetext{
${ }^{10}$ Recall that the condition to rule out a rollover crisis is that the debt Laffer curve is above the financing needs as $b_{T 1} \rightarrow \infty$.

The words "turn into" for a good reason. Let $\hat{\delta}$ be the cutoff such that a rollover crisis is possible for $\delta>\hat{\delta}$ and not possible for $\delta<\hat{\delta}$. As $\delta \uparrow \hat{\delta}$ the value of $b_{T}$ in the bad equilibrium goes to infinity and the bond price in the bad equilibrium goes to zero, which are the conventional values used to describe a rollover crisis.
} 
Consider a candidate equilibrium value for $b_{T}$ and suppose for simplicity that the policy rule is constant, so $z_{T-1}=\hat{z}$. Then, we can use the budget constraint to solve for $b_{T-1}$ :

$$
b_{T-1}=\frac{\hat{z}+Q_{T-1}\left(b_{T}\right) b_{T}}{\kappa+(1-\delta) Q_{T-1}\left(b_{T}\right)} .
$$

Given $b_{T-1}$, we can use the rational expectations condition (2) to solve for $q_{T-2}$ :

$$
q_{T-2}=(1-\lambda) \beta\left[\kappa+(1-\delta) Q_{T-1}\left(b_{T}\right)\right]+\lambda \Psi\left(b_{T-1}\right),
$$

where the function $\Psi$ is defined in (8). The pair $\left(b_{T-1}, q_{T-2}\right)$ is consistent with equilibrium at $T-1$ if and only if it can be derived from the two conditions above for some $b_{T}$. The locus of pairs $\left(b_{T-1}, q_{T-2}\right)$ derived in this way is plotted in panel A of Figure 4 for the numerical example above, setting $\delta=0.5$.

This construction identifies four regions for the debt level $b_{T-1}$ : the interval $\left[0, b_{L}\right)$ is the safe region in which only an equilibrium exists and it features bond prices close to 1 ; the interval $\left[b_{L}, b_{H}\right]$ is the multiplicity region where two stable equilibria are possible; the interval $\left(b_{H}, b_{M A X}\right]$ is the region in which a unique equilibrium is possible, but it features low bond prices; finally in the interval $\left(b_{\text {MAX }}, \infty\right)$ there is no equilibrium consistent with debt repayment at time $T-1$. Using the graph in panel A of Figure 4 we can construct a bond price function $Q_{T-2}\left(b_{T-1}\right)$ by selecting an equilibrium at time $T-1$ in the multiplicity region. An example of such a bond price function is shown in panel B of Figure 4. That bond price function is derived selecting the good equilibrium for $b_{T-1} \leq \hat{b}$ and the bad equilibrium for $b_{T-1}>\hat{b}$.

In the next section, we extend this type of construction to a fully dynamic model with a non-constant policy rule.

\section{Debt Dynamics}

We now turn to analyze debt dynamics. As in the last section, we focus on a process for the primary surplus in which resolution of uncertainty happens with Poisson probability. However, we remove the terminal date $T$ so as to have a stationary environment. For analytical convenience, we turn to continuous time, so the dynamics before the Poisson event can be analyzed by studying two ordinary differential equation (ODEs).

Let us briefly go over the continuous time version of our model. Bonds issued at time $t$ pay the coupon $\kappa e^{-\delta(\tau-t)}$ for $\tau>t$. We still assume $\kappa=r+\delta$, so the bond price is 1 when there is no default risk.

The primary surplus process closely mirrors the one in Section III. Before the resolution of uncertainty the primary surplus is given by the nondecreasing function

$$
z=h(b)
$$

that is bounded above by $\bar{z}$. Uncertainty is resolved with Poisson arrival rate $\lambda$. At the time of the resolution of uncertainty, the random variable $Z$ is drawn from the cumulative distribution function (c.d.f.) $F(Z)$ and the primary surplus is constant 

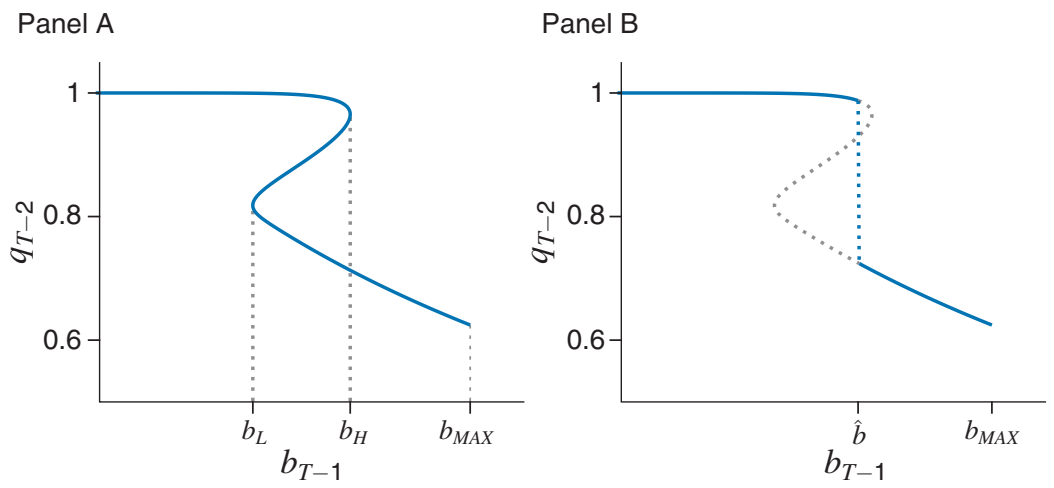

Figure 4. Constructing the Bond Schedule at $T-2$

at $z=r Z$ from then on. If $Z \geq b$ default is avoided and the bond price equals 1 , if $Z<b$ bondholders obtain the recovery value $\phi Z$, with $\phi<1$. So the bond price immediately before the resolution of uncertainty is

$$
q=\Psi(b) \equiv 1-F(b)+\frac{\phi}{b} \int_{0}^{b} Z d F(Z)
$$

which is analogous to equation (8).

Before the Poisson event, the government budget constraint (1) and the bond pricing condition (2) take the form

$$
\begin{gathered}
z+q(\dot{b}+\delta b)=\kappa b, \\
r q=\kappa-\delta q+\lambda(\Psi(b)-q)+\dot{q} .
\end{gathered}
$$

Here we are restricting attention to continuous paths for the price $q$ before the Poisson event. This is equivalent to assuming no sunspot. Sunspots are discussed in Section IVE.

Our objective here is to construct Markov equilibria in which, before the resolution of uncertainty, the bond price is a function of the stock of bonds, denoted by $Q(b)$. In order to construct a Markov equilibrium, we proceed in two steps. First, we characterize solutions to the ODEs $(11)-(12)$ in $(q, b)$, given appropriate boundary conditions. Next, we use these solutions to construct the function $Q(b)$.

\section{A. Boundary Conditions}

Two boundary conditions are possible: either the economy converges to a stable steady state or it converges to default before the Poisson event. Let us look at both cases.

Convergence to a Steady State.--Steady states of the system (11)-(12) are found at the intersection of the loci $\dot{q}=0$ and $\dot{b}=0$. The $\dot{q}=0$ locus is given by

$$
q=\frac{\kappa+\lambda \Psi(b)}{r+\delta+\lambda}
$$


and is downward sloping since $\Psi^{\prime}(b)<0$. The $\dot{b}=0$ locus is given by

$$
q=\frac{\kappa b-h(b)}{\delta b}
$$

and is decreasing if and only if

$$
h^{\prime}(b)>\kappa-\delta q .
$$

We assume that there is a range of $b$ for which (15) is satisfied, so the $\dot{b}=0$ locus is decreasing in that range. As we shall see, this assumption is necessary to ensure the existence of a stable steady state. On the other hand, our assumption that $h$ is bounded above at $\bar{z}$ implies that for high enough levels of debt (15) is violated and the $\dot{b}=0$ locus is increasing.

Panel A of Figure 5 shows steady states of a numerical example. The parameters of this example are described in Section IVC. The blue line represents the $\dot{q}=0$ locus, the brown line the $\dot{b}=0$ locus. The example features two steady states. A low-debt steady state, in which bond prices are high, debt issuances $\delta q b$ cover a large fraction of the coupon payments $\kappa b$, and the government runs a low primary surplus, consistent with its policy rule $h(b)$. And a high-debt steady state, in which bond prices are low and debt issuances cover a smaller portion of coupon payments, so the government needs to run a larger surplus. Notice that multiplicity of steady states is different from multiplicity of equilibria, as we shall see below.

For a steady state to serve as a boundary condition it must be locally stable. The following lemma provides a necessary and sufficient condition for local saddle-path stability.

LEMMA 2 (Stability): A steady state with positive debt is a saddle point if and only if the $\dot{b}=0$ locus is downward sloping and steeper than the $\dot{q}=0$ locus, or equivalently,

$$
h^{\prime}(b)>\kappa-\delta q-\frac{\delta \lambda}{r+\delta+\lambda} \Psi^{\prime}(b) b .
$$

In the case of no default risk, with $q=1$ and $\lambda \Psi^{\prime}(b)=0$, condition (16) reduces to $h^{\prime}(b)>r$. In the literature, stability conditions analogous to $h^{\prime}(b)>r$ are used to describe a "Ricardian regime" in which fiscal policy adjusts to keep the debt stable (Leeper 1991). However, once default risk is present, local stability requires a stronger condition. Condition (16) is stronger than $h^{\prime}(b)>r$ for two reasons. First, the average cost of debt servicing (coupon payments net of receipts from replacing depreciated bonds) is higher with default risk, since $\kappa-\delta q=r+\delta(1-q)>r$. Second, the marginal cost of debt servicing is higher than its average cost because $q$ is endogenous and decreasing in $b$. This effect is captured by the last term in (16), where $\Psi^{\prime}(b)<0$.

The low-debt steady state in Figure 5 is saddle-path stable, as we can see from the relative slopes of the $\dot{b}=0$ and $\dot{q}=0$ loci. In panel B of Figure 5, we plot, in green, dynamic paths that converge to the low-debt steady state. Looking at the 
Panel A

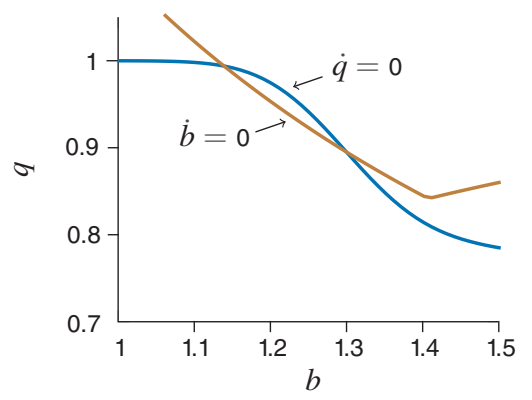

Panel B

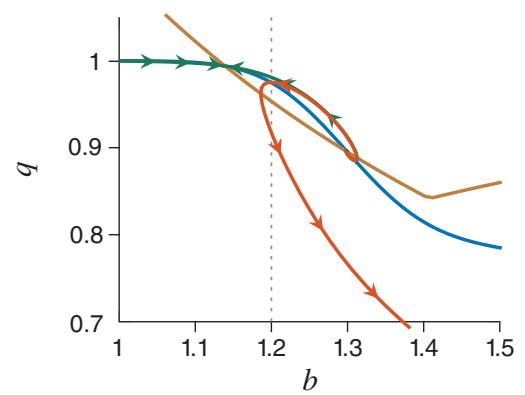

Figure 5. Continuous Time Model: Phase Diagram

dynamic paths near the high-debt steady state, we can see that it is unstable and features oscillating dynamics moving away from the steady state. The next proposition shows that this configuration with one stable and one unstable steady state is typical: when there is one stable steady state, there is always another, unstable, steady state, with higher debt.

PROPOSITION 5 (Multiple Steady States): If there exists a stable steady state with positive debt, then there exists an unstable steady state with higher debt.

The existence of an unstable steady state is tightly related to the upper bound for the primary surplus $z$. That upper bound means that the fiscal policy rule is unresponsive at high enough debt levels, that is, $h^{\prime}(b)=0$ for $b$ large enough. This means that at high enough debt the locus for $\dot{b}=0$ is increasing and must intersect the locus for $\dot{q}=0$ which is decreasing. At that intersection, condition (16) is necessarily violated, giving instability.

Of course, more than two steady states are possible. For simplicity, in the remainder of this section, we focus our attention on economies with two steady states as in Figure 5, which we denote $\left(b^{L}, q^{L}\right)$ and $\left(b^{H}, q^{H}\right)$.

Convergence to Default.-Convergence to a steady state is not the only possible terminal condition. The economy can also follow a path leading to certain default at some finite date $\hat{t}$, before the resolution of uncertainty. In continuous time, default can occur before the resolution of uncertainty only if $q$ reaches 0 at $t=\hat{t}$, because as long as $q$ is positive there always exists a $\dot{b}$ that satisfies the budget constraint (11). Denote by

$$
v=q b
$$

the value of debt. The ODEs $(11)-(12)$ in $(q, b)$ can be transformed into ODEs in $(q, v)$ (see the online Appendix for details). The presence of recovery means that, at the moment of default, bondholders expect a positive recovery value $\hat{v}>0$ and rational expectations require that $v$ converge continuously to $\hat{v}$ as $t \rightarrow \hat{t}$. Therefore, to find the path leading to default before the resolution of uncertainty, we just need to solve the ODEs in $(q, v)$ with terminal conditions $(0, \hat{v})$. 
It remains to determine the terminal value $\hat{v}$. Since $q$ converges to zero and $q b$ converges to a positive value, $b$ will diverge to $\infty$ as we approach default. Therefore, at some point $b$ will be large enough that the current surplus is at its upper bound $\bar{z}$ and the expected recovery is $\Psi(\bar{Z}) \bar{Z}=\phi E[Z]$. The recovery value at the moment of default is then

$$
\hat{v}=\phi \frac{\bar{z}+\lambda E[Z]}{r+\lambda} .
$$

Going back to panel B of Figure 5, we see, in red, a dynamic path that spirals out of the high-debt steady state and eventually leads to ever increasing debt and ever lower bond prices. The limit of that path has $q \rightarrow 0$ and $b \rightarrow \infty$ along a hyperbola with $q b$ constant. ${ }^{12}$

\section{B. Multiple Markov Equilibria}

Let us now construct a Markov equilibrium for the example in Figure 5. That is, an equilibrium in which, before the Poisson event, the price is a function $Q(b)$ of the initial debt level $b$. To construct a Markov equilibrium, we proceed in two steps.

In the first step, we construct two candidate functions $Q^{+}$and $Q^{-}$. Solve the ODE backward from the low-debt steady state $b^{L}$ in both directions, following the green paths. In the direction to the right of $b^{L}$, stop the first time that $\dot{b}$ changes sign, i.e., stop at the first bend of the spiral. Call the stopping point $b^{+}$. This construction defines a function $Q^{+}(b)$ on the domain $\left(\infty, b^{+}\right.$. A similar construction can be done moving backward from any point $(b, q)$ that satisfies $b \geq \bar{Z}, h(b)=\bar{z}$, and $q b=\hat{v}$. This gives us dynamics consistent with convergence to default, following the red path in the figure. Again, we stop at the value $b^{-}$at which $\dot{b}$ switches sign. This yields a function $Q^{-}(b)$ on the domain $\left[b^{-}, \infty\right) \cdot{ }^{13}$

In the second step, we construct a Markov equilibrium selecting from the two functions just defined. For this construction to be consistent with equilibrium dynamics, we need to pick a cutoff $\hat{b}$ and select the $Q^{+}$function to the left of $\hat{b}$ and the $Q^{-}$function to the right of $\hat{b}$. This follows because if we select on the $Q^{+}$function we have $\dot{b}<0$ and so we stay to the left of $\hat{b}$ from then on, while if we select on the $Q^{-}$function we have $\dot{b}>0$ and so we stay to the right of $\hat{b}$ from then on.

The two steps of our construction are shown in the two panels of Figure 6. Panel A shows the functions $Q^{-}$and $Q^{+}$, and panel B shows the selected function $Q$.

The way we just constructed a Markov equilibrium is not special to the example considered and extends to all economies that feature two steady states, one of which is stable, as shown in the next proposition.

\footnotetext{
${ }^{12}$ One can wonder whether other types of terminal conditions are possible. In a configuration with two steady states as in Figure 5, no other terminal condition is possible, because all paths different from those considered either lead to $q>1$, which is inconsistent with the investors' transversality conditions, or lead to $q=0$ at which point default occurs and the value $q b$ has either diverged or converged to a value different from $\hat{v}$.

${ }^{13}$ Following a spiraling path would be inconsistent with the Markov property because in equilibrium the economy will feature two different prices $q$ at two different points in time in which $b$ is the same.
} 

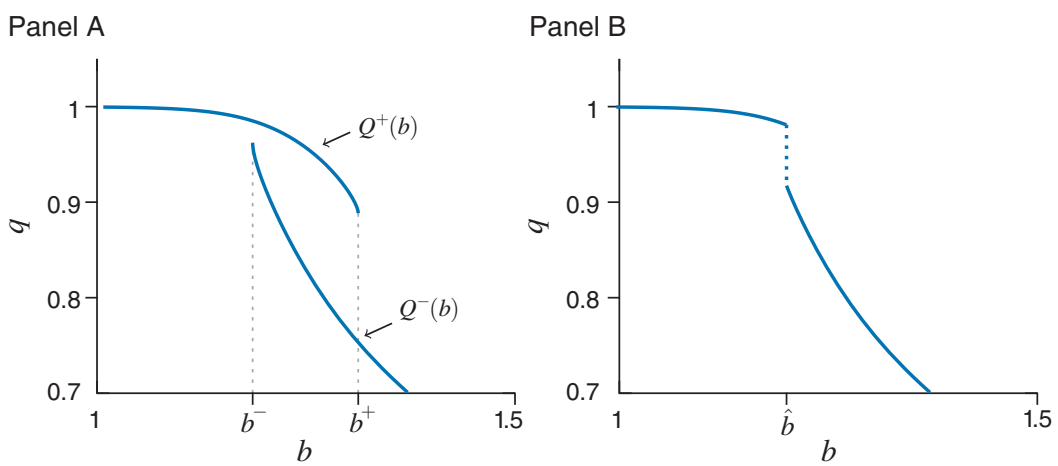

Figure 6. Continuous Time Model: Constructing a Markov Equilibrium

PROPOSITION 6 (Markov Equilibria): Suppose there is a stable steady state $\left(b^{L}, q^{L}\right)$ and an unstable steady state $\left(b^{H}, q^{H}\right)$, with $b^{L}<b^{H}$. Then there are two functions $Q^{-}:\left[b^{-}, \infty\right) \rightarrow \mathbb{R}_{+}$and $Q^{+}:\left(-\infty, b^{+}\right] \rightarrow \mathbb{R}_{+}$with $b^{-} \leq b^{H} \leq b^{+}$ with $Q^{-}(b)<Q^{+}(b)$ for $b \in\left[b^{-}, b^{+}\right]$. For any threshold $\hat{b} \in\left[b^{-}, b^{+}\right]$there is a Markov equilibrium with

$$
Q(b)= \begin{cases}Q^{+}(b) & \text { for } b \leq \hat{b} \\ Q^{-}(b) & \text { for } b>\hat{b}\end{cases}
$$

Debt dynamics satisfy $\dot{b}<0$ for $b<\hat{b}$ and $\dot{b}>0$ for $b>\hat{b}$.

Proposition 6 allows for two possible cases. Either $b^{-}<b^{+}$or $b^{-}=b^{+}$. In the first case, the domains of the two functions $Q^{-}$and $Q^{+}$overlap and there are multiple Markov equilibria because any intermediate threshold $\hat{b} \in\left(b^{-}, b^{+}\right)$can be chosen to switch from $Q^{+}$to $Q^{-}$. This is the case of multiple Markov equilibria illustrated in Figure 5. However, it is also possible that the values $b^{-}$and $b^{+}$satisfy $b^{-}=b^{+}$, in which case the equilibrium is unique. Figure 7 illustrates this second case. In both cases, the low-debt steady state is saddle-path stable and the high-debt steady state is not, as can be inspected from the slopes of the $\dot{b}=0$ and $\dot{q}=0$ loci. But in the second case the high-debt steady state is a simple source, with no oscillating dynamics. So in this case the two functions do not overlap and the equilibrium is unique.

Although in the example of Figure 7 the equilibrium is unique, long-run dynamics are very sensitive to initial conditions. If we start just below the high steady state, debt converges to the low steady state; if we start just above it, debt grows until certain default. This formalizes the notion that the economy can have a tipping point where debt-sustainability concerns drastically alter debt dynamics.

Going back to the case of multiple equilibria, the next proposition gives a sufficient condition for oscillating dynamics near the unstable steady state, and thus for multiple equilibria. 


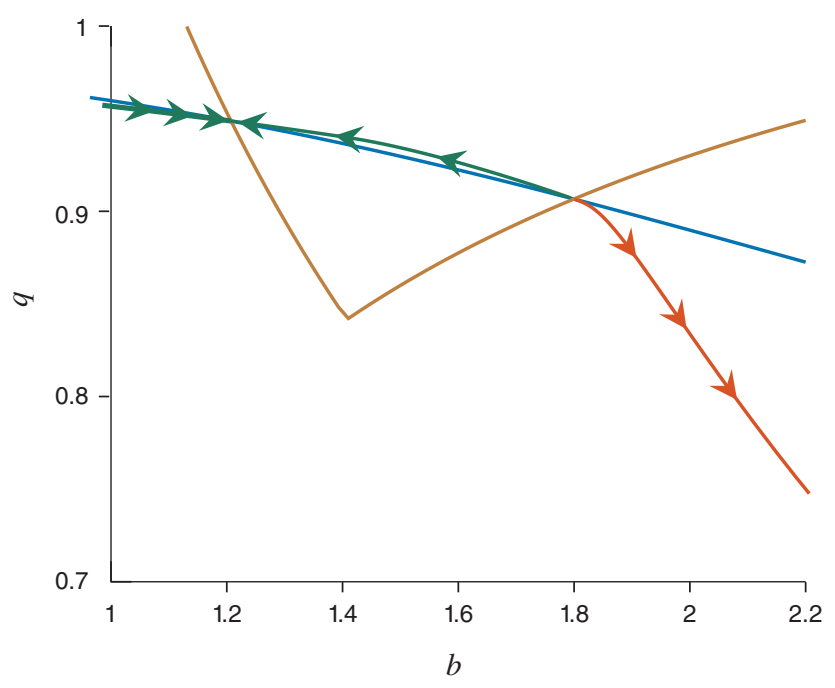

Figure 7. An EXAMPLE OF UNIQUENESS

PROPOSITION 7 (Sufficient Condition for Multiplicity): Suppose that at the unstable steady state

$$
4 \delta \lambda \Psi^{\prime}\left(b^{H}\right) q^{H} b^{H}+\left(\delta q^{H}+h^{\prime}\left(b^{H}\right)+\lambda \Psi\left(b^{H}\right)\right)^{2}<0,
$$

then $b^{-}<b^{+}$and there are multiple Markov equilibria.

The condition in the proposition is sufficient but not necessary. Multiple equilibria can also arise when both eigenvalues are real and positive, if the nonlinearity of the system generates oscillating global dynamics that converge to monotone local dynamics as we approach $b^{H}$.

An advantage of the continuous model of this section is that the same curves capture both the equilibrium relation between debt and bond prices and the equilibrium dynamics of both, as illustrated in Figures 5 and 6. In particular, Figure 5 shows that our model has a property which we call "eventual uniqueness." Even if the economy starts in the interval $\left[b^{-}, b^{+}\right]$, if we follow the good path leading to the low-debt steady state for long enough, eventually the economy exits the interval of multiplicity and multiple equilibria are no longer possible. The same is true if the economy follows the bad path. For some time the good path may remain available, but there is a point of no return. A self-fulfilling crisis driven by bad expectations eventually turns into an insolvency crisis with bad fundamentals.

This discussion has implications for policy interventions such as the "whatever it takes" announcement mentioned in the introduction. In the model, a lender-of-lastresort can eliminate the bad equilibrium by committing to purchase bonds issued by the sovereign at a price above the bad equilibrium price. Such a commitment eliminates the bad equilibrium path and so uniquely selects the good equilibrium, without the need for equilibrium intervention by the lender-of-last-resort. This is a 
common result in models with multiple equilibria. The additional message here is that delaying an intervention is dangerous, as $b$ will keep increasing and eventually cross the $b^{+}$threshold after which intervening is no longer costless. One can also think of extensions of the model in which the lender-of-last-resort is uncertain whether we are to the right or to the left of $b^{+}$. In those circumstances, the lenderof-last-resort will need to take into account the possibility of actual purchases being needed in equilibrium to move back the economy in the region where the good equilibrium path is achievable. Extensions along these lines could be used to capture the dilemmas faced by sovra-national lenders like the IMF or the ECB when facing the possibility of self-fulfilling equilibria.

\section{A Slow Moving Crisis}

The numerical example used for Figures 5 and 6 is loosely built on the case of Italy in 2011. We can reinterpret the variable $b$ as the ratio of debt to GDP and $z$ as the ratio of the primary surplus to GDP. It would be easy to add deterministic growth to the model, but real growth in Italy in the period considered was very low, so we can safely assume zero growth before the Poisson event. Growth after the Poisson event is implicit in the distribution of $Z$. The fiscal rule is chosen to fit the observed relation between the debt-to-GDP ratio and the primary surplus in Italy in the period 1988-2012. A simple linear regression of the primary-surplus-to-GDP ratio on the debt-to-GDP ratio for that sample period yields $\alpha_{0}=-0.13$ and $\alpha_{1}=0.135$. We assume an upper bound at $\bar{z}=6 \%$ and use the rule

$$
z=\min \left\{\alpha_{0}+\alpha_{1} b, \bar{z}\right\}
$$

We choose $\delta=1 / 7$ to match the average maturity of Italian government debt, which is about 7 years. The real interest rate is set at $r=2 \%$. We choose a recovery of $\phi=0.5$ and assume that $Z$ is normally distributed. The mean and variance of $Z$ are calibrated so that in the low-debt steady state debt is essentially safe, with a spread of 10 basis points, and the high-debt steady state is at $b=1.3$. The value of $\lambda$ is set to 0.1 .

Suppose the economy starts with a stock of debt $b_{0}=1.2$, which is roughly the debt-to-GDP ratio of Italy in 2011. As we have seen, with the chosen parameters, 1.2 is in the multiplicity region. The dynamics of bond spreads, of the primary surplus, and of debt-to-GDP are plotted in Figure 8. We can imagine Italy following a path of slow debt reduction, as in the good equilibrium of Figure 5. Then investors' sentiment shift unexpectedly and we switch to a Markov equilibrium with $\hat{b}<1.2$ and the economy starts following the bad equilibrium path of Figure 5. This sentiment shift causes spreads to jump from $30 \mathrm{bp}$ to $150 \mathrm{bp}$ on impact. ${ }^{14}$ This puts the economy on a path of gradually faster debt accumulation, increasing spreads and an increasing fiscal effort due to the fiscal rule. Therefore, the model can account for a crisis in which spreads increase suddenly and sharply, but the country affected

\footnotetext{
${ }^{14}$ Yields on 10-year Italian bonds went from 4.75 in May 2011 to 7.6 in November of the same year. Similar magnitudes of "sentiment" shocks can be read off the estimate of the effects of OMT announcements in Krishnamurthy, Nagel, and Vissing-Jorgensen (2013).
} 


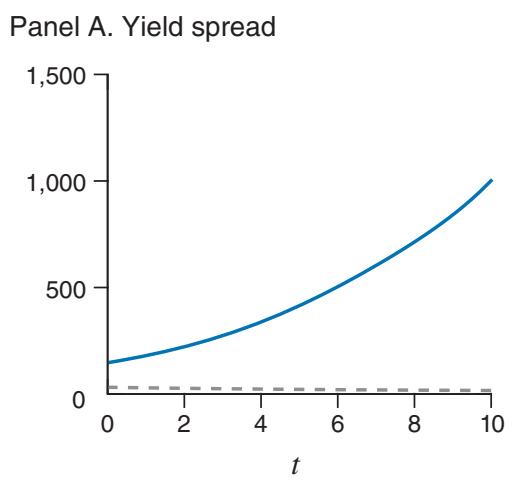

Panel B. Debt

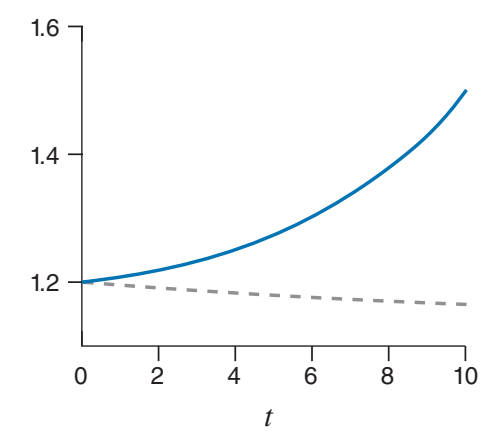

Figure 8. Two Equilibrium Paths Starting at $b=1.2$

keeps issuing debt on financial markets for a while and in which debt dynamics only slowly incorporate the effect of the higher spreads. ${ }^{15}$

The plots in Figure 8 help identify the main difference between our slow moving crises and the self-fulfilling crises in Calvo (1988) and Cole and Kehoe (2000) in terms of empirical predictions. The main difference is the possibility of having spreads that increase sharply in the short run even though short-run default probabilities increase only gradually. The crucial ingredients here are the fact that the model has more than two periods and the presence of long-term debt, so anticipations of future default can move spreads substantially in the short run.

\section{Regions}

The model allows us to study how changes in parameters affect debt dynamics. As an illustration, consider our main numerical example. We can then vary the responsiveness of the policy rule $\alpha_{1}$ and see how the multiplicity interval $\left[b^{-}, b^{+}\right]$ varies. This exercise is represented in Figure 9. The interval $\left[b^{-}, b^{+}\right]$is represented by the yellow area labeled "two equilibria." The safe region $b<b^{-}$in which only convergence to the low-debt steady state is possible is represented by the blue area labeled "Only good equilibrium." The region $b>b^{+}$in which the only equilibrium leads to certain default is represented by the red area labeled "Only bad equilibrium." The figure shows that increasing the responsiveness of the policy rule, shifts up the interval $\left[b^{-}, b^{+}\right]$. In the example, the size of the multiplicity region does not seem visibly affected by the policy rule, only its position. Beyond a certain value of $\alpha_{1}$ the benefits in term of increasing the safe region are dampened and, at some point the values of $b^{-}$and $b^{+}$appear flat in $\alpha_{1}$. That is simply due to the fact that we are keeping the upper bound $\bar{z}$ unchanged as we move $\alpha_{1}$.

A similar exercise can be done to study the effects of changing debt maturity and is illustrated in Figure 10. The figure shows that maturity has clear effects both on the size and on the position of the multiplicity interval. In particular, when $\delta$ is

\footnotetext{
${ }^{15}$ One prominent feature of the Italian crisis missing from Figure 8 is the increase in spread volatility. For that, see Section IVE on sunspots.
} 


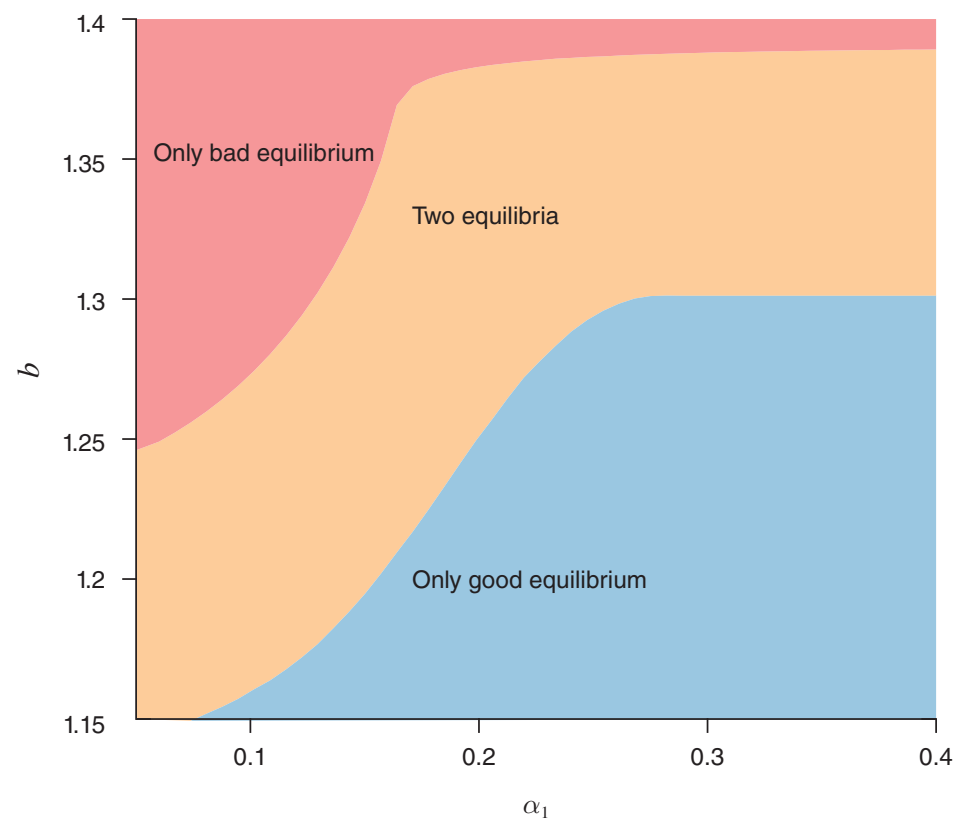

Figure 9. Regions of Policy Parameter $\alpha_{1}$ and Initial Debt $b$ with Unique Good Equilibrium, Two EQUILIBRIA, OR UNIQUe BAD EQUILIBRIUM

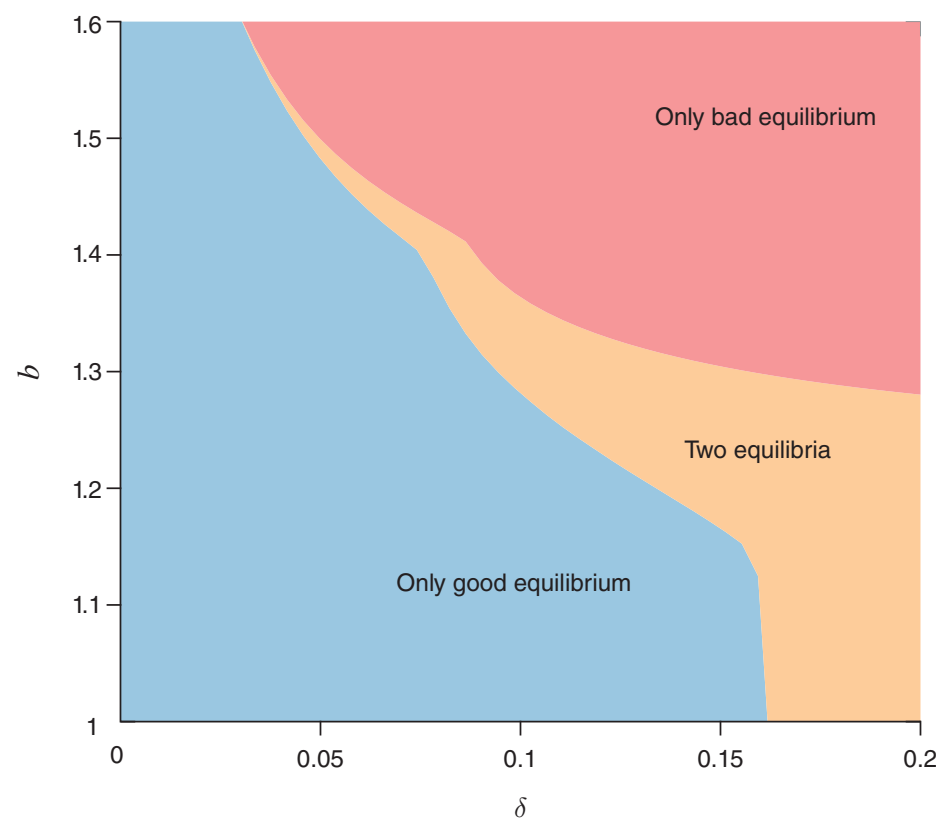

Figure 10. Regions of Maturity and Initial Debt with Unique Good Equilibrium, Two Equilibria, or UNIQUE BAD EQUILIBRIUM

low enough the multiplicity region disappears. Moreover, when $\delta$ is large enough, we reach a point where $b^{-}=0$, so the bad equilibrium can be reached from any positive level of debt and the safe region vanishes. 


\section{E. Sunspots}

In the equilibria constructed so far, multiple equilibrium paths are only possible at $t=0$, when the Markov equilibrium is selected, i.e., when the cutoff $\hat{b}$ is chosen. After a Markov equilibrium is selected, the model dynamics are deterministic and either converge to the stable steady state or to default.

However, once multiplicity is possible, we can also construct sunspot equilibria in which, as long as $b$ remains in some interval $\left[b^{-}, b^{+}\right]$, the equilibrium path can shift randomly between a path leading to a stable steady state and a path leading to default. A simple form of sunspot equilibrium is an equilibrium in which there is an additional, non-payoff-relevant state $\omega \in\left\{\omega^{L}, \omega^{H}\right\}$ and switches between the two states occur with Poisson intensity $\pi$. We can then construct Markov equilibria in which the bond price function is $Q(b, \omega)$, so the price depends on the sunspot.

Figure 11 illustrates a sunspot equilibrium, based on the same parameters used for Figures 5 and 6 , in which, if we enter the region of multiplicity the economy selects always the high price equilibrium if $\omega=\omega^{H}$ and always the low price equilibrium if $\omega=\omega^{L}$. Finding the functions $Q^{-}$and $Q^{+}$from which to select involves calculations similar to the ones done above, but the ODE for the bond price, equation (12), has to be changed to incorporate investors' expectations regarding the effects of the sunspot. In particular, the ODE used to find the $Q^{+}$function is now

$$
r q=\kappa-\delta q+\lambda(\Psi(b)-q)+\pi\left(Q^{-}(b)-q\right)+\dot{q}
$$

when $b$ is in the interval $\left[b^{-}, b^{+}\right]$, and is (12) when $b<b^{-}$. A symmetric ODE characterizes the $Q^{-}$function. So finding an equilibrium now requires solving a fixed point problem involving the functions $Q^{-}, Q^{+}$and the points $b^{-}, b^{+}$.

Notice the implications of a sunspot equilibrium for volatility. An economy that starts in the region $\left[b^{-}, b^{+}\right]$will display high volatility, as the bond price jumps in response to the sunspot. However, if the good shock lasts long enough, the economy can move to the right of the $b^{-}$threshold, switch to a low volatility regime, and converge to the low debt steady state. This observation is clearly related to the eventual uniqueness property identified above.

We could expand the analysis of sunspot equilibria to study the effects of anticipated policy interventions on volatility. In particular, one can think of a regime in which investors expect, with some probability, the announcement of a "whatever-it-takes" policy that would move the economy permanently on the good equilibrium path. Before such an announcement, changes in the probability of the announcement will change both the level and the volatility of spreads. We leave this extension to future work.

\section{F. Back to the Debt Laffer Curve}

There is a clear similarity between the construction of the Markov equilibrium bond price function in Figure 6 and the construction of the bond price function in Figure 4 for the discrete time model of Section III. What is less immediate is the role, in the continuous time model, of the debt Laffer curve that played a central role in the analysis of Sections II and III. In a 

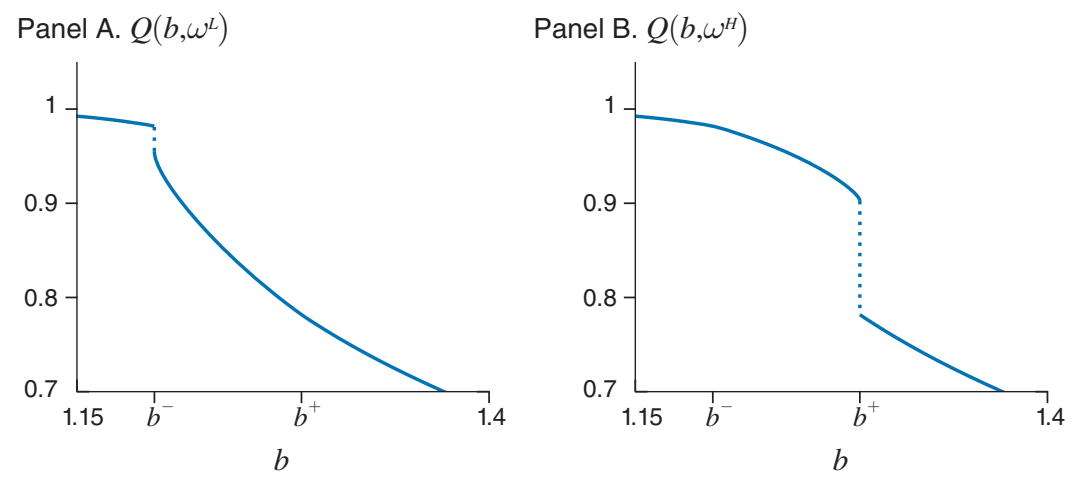

Figure 11. Continuous Time Model: A Sunspot Equilibrium

continuous time model the debt stock $b$ cannot jump and so the resources from bond issuance

$$
Q(b)(\dot{b}+\delta b)
$$

are a linear function of the flow of new bonds issued $\dot{b}$. This seems to suggest that the debt Laffer curve is always increasing in the continuous time model. However, if we look at Figure 6 , we realize that this argument fails exactly at $b=\hat{b}$, where the function $Q$ has a discontinuity. At that point, if we choose $\dot{b}<0$ we go in the direction of $b<\hat{b}$ and thus select the price $Q^{+}(\hat{b})$, while if we choose $\dot{b}>0$ we go in the direction of $b>\hat{b}$ and we must select $Q^{-}(\hat{b})<Q^{+}(\hat{b})$. Therefore the debt Laffer curve, as a function of $\dot{b}$, takes the form depicted in Figure 12. So, also in the continuous time model a multipeaked Laffer curve is crucial to produce multiplicity.

\section{Optimizing Government}

In this section, we consider a model analogous to the stationary model from the previous subsection, but derive fiscal policy endogenously from an optimizing government. The goal is to show that a similar form of equilibrium multiplicity is also present here.

We keep the continuous time, infinite horizon environment of the last section: the country sells long-term bonds with a coupon $\kappa=r+\delta$ that decays at rate $\delta$ to risk-neutral lenders with discount rate $r$. The surplus process is determined by the decisions of an optimizing government with additively separable preferences

$$
\int_{0}^{\infty} e^{-r t} U(c(t)) d t
$$

where $c$ is government spending and $U(c)=c^{1-\sigma} /(1-\sigma)$, with $\sigma>0$. The government receives a random stream of tax revenues $y$. Uncertainty on $y$ is resolved in two stages. In the first stage, the government receives a constant $\bar{y}$. At some random date, with Poisson arrival rate $\lambda$, we enter the second stage. At that date, the random 


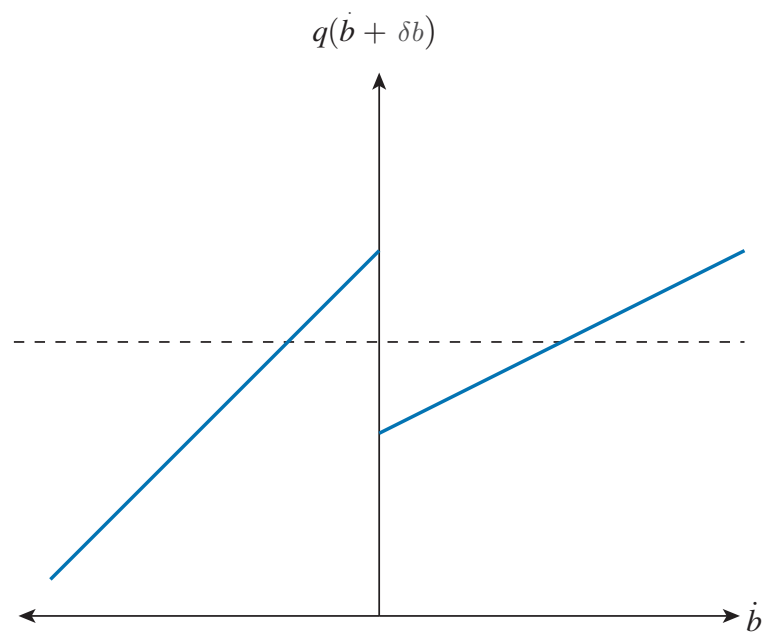

Figure 12. Debt Laffer Curve in Continuous Time, at $b=\hat{b}$

variable $Y$ is drawn from a continuous distribution with c.d.f. $H(Y)$. From then on, tax revenues are $y=Y$.

After the Poisson event, the government can choose to repay or default. If the government defaults, the tax revenue is reduced to $\eta Y$ forever, with $\eta<1$ and investors recover a proportion of the tax revenue $\zeta Y$, with $\eta+\zeta<1$. The country repays if and only if the following condition is satisfied: ${ }^{16}$

$$
Y-r b \geq \eta Y
$$

The government utility at the moment of the Poisson event, immediately before the resolution of uncertainty, is

$$
W(b)=\frac{1}{r} \int_{0}^{\infty} U(\max \{Y-r b, \eta Y\}) d H(Y) .
$$

With a simple change of variable, we can characterize bond prices using the notation of the last section. Define

$$
Z \equiv \frac{1-\eta}{r} Y
$$

and notice that the c.d.f. of $Z$ is $F(Z)=H\left(\frac{r}{1-\eta} Z\right)$. Condition (17) is then equivalent to $Z \geq b$ and investors' recovery value is, in present value, $\phi Z$, where $\phi=\zeta /(1-\eta)<1$. The pricing condition before the Poisson event is then identical to equation $(12)$.

\footnotetext{
${ }^{16}$ We can assume that the country is excluded from financial markets after default, or that it is allowed to save at the rate $r$. Since the country and the investors have the same discount factor and there are no further shocks, the results are identical under both assumptions.
} 
Given the presence of a positive recovery rate, we must introduce a bound on debt issuance to ensure that the borrower's problem is well defined. We do so by assuming that if $b$ reaches some upper bound $\bar{b}$, before the Poisson event, renegotiation takes place between the borrower and its creditors. Following renegotiation, the government agrees to receive a net transfer $\tau$ (possibly negative) in all periods before the Poisson event and not to issue any additional debt, so the creditors will receive the expected value $\Psi(\bar{b}) \bar{b}$ when uncertainty is resolved.

With these preliminary results in place, we can turn to characterizing Markov equilibria before the Poisson event.

\section{A. Markov Equilibria}

A Markov equilibrium is a price function $Q(b)$ and a government consumption function $C(b)$ such that (i) government behavior is optimal taking the price function as given; (ii) the price function satisfies rational expectations given government behavior. We also require $Q$ to be piecewise differentiable. Just as in Section III the function $Q$ can have a point of discontinuity at a threshold that divides a path with falling and rising debt.

Let $V(b)$ denote the value function before the resolution of uncertainty. The budget constraint before the resolution of uncertainty is

$$
c+\kappa b=\bar{y}+q(\dot{b}+\delta b)
$$

so the Hamilton-Jacobi-Bellman equation associated to the government's optimization problem is

$$
0=\max _{c \geq 0}\left\{u(c)+V^{\prime}(b)\left(\frac{\kappa b-\bar{y}+c}{Q(b)}-\delta b\right)+\lambda(W(b)-V(b))-r V(b)\right\}
$$

with first-order condition for an interior solution

$$
Q(b) u^{\prime}(c)=-V^{\prime}(b)
$$

The bond price must satisfy (12) along the path induced by government policy $C(b)$. Differentiating $q(t)=Q(b(t))$ along an equilibrium path gives $\dot{q}=Q^{\prime}(b) \dot{b}$ where $Q^{\prime}(b)$ can be interpreted as the left derivative if $\dot{b}<0$ and the right derivative if $\dot{b}>0$. Rewriting the budget constraint (12) in terms of $Q$ then gives

$$
Q^{\prime}(b)\left(\frac{\kappa b-\bar{y}+c}{Q(b)}-\delta b\right)=(r+\delta+\lambda) Q(b)-\kappa-\lambda \Psi(b) .
$$

Equations (20) and (21) give a system of ordinary differential equations for $V(b)$ and $Q(b)$. There are two boundary conditions. The first is at $b=\underline{S}$, the lowest value in the support of $S$. This represents the safe level of debt where default is avoided. The second boundary condition is at the upper bound $\bar{b}$, where renegotiation occurs. 


\section{B. An Example}

We construct a numerical example displaying multiple equilibria. The example is meant as an illustration, not a calibration. The parameters are set to

$$
r=0.1, \quad \delta=2, \quad \lambda=0.1, \quad \eta=0.5, \quad \zeta=0.1, \quad \sigma=4
$$

The distribution of $Y$ is chosen such that $S$ is uniformly distributed on $[10,100]$. The value of $\bar{y}$ is set so that the model admits a steady state at $b=0$ with no default and $q=1$. The upper bound for debt is $\bar{b}=30$ and we assume that upon reaching this level, investors provide a transfer to the borrower equal to $\tau=(1 / 2) \lambda \Psi(\bar{b}) \bar{b}$. In other words, they split the residual value of debt equally.

To find equilibria we solve the ODEs (20) and (21), first looking for decreasing paths for $b$ that converge to $b=0$ and next for increasing paths that converge to $b=\bar{b}$. The first solution gives the functions $C^{-}(b)$ and $Q^{-}(b)$ plotted in panels $\mathrm{A}$ and $\mathrm{C}$ of Figure 13 and the function $V^{-}(b)$ in Figure 14. The second solution gives the functions $C^{+}(b), Q^{+}(b)$ in panels B and D of Figure 13 and the function $V^{+}(b)$ in Figure 14. The dashed green lines in panels A and B of Figure 13 represent the consumption levels that yield $\dot{b}=0$. In the figures we identify two cutoffs, $b^{\prime}$ and $b^{\prime \prime}$. The first is the cutoff at which $V^{-}(b)=V^{+}(b)$. The second cutoff solves the equation

$$
\bar{y}+Q^{+}(b) \delta b=\kappa b .
$$

This condition implies that it is not feasible for the government to choose $\dot{b}<0$ for $b>b^{\prime \prime}$, if the price schedule is $Q^{+}(b)$, as the budget constraint (19) would give negative consumption. We can check that the dashed green line in panel B of Figure 13 crosses zero at $b^{\prime \prime}$.

The following proposition characterizes Markov equilibria for our example.

PROPOSITION 8: For any $\hat{b} \in\left(b^{\prime \prime}, b^{\prime}\right]$, there is a Markov equilibrium with

$$
Q(b)=\left\{\begin{array}{l}
Q^{-}(b) \text { for } b \leq \hat{b} \\
Q^{+}(b) \text { for } b>\hat{b}
\end{array} \text { and } C(b)=\left\{\begin{array}{l}
C^{-}(b) \text { for } b \leq \hat{b} \\
C^{+}(b) \text { for } b>\hat{b}
\end{array}\right.\right.
$$

When we are to the left of both $b^{\prime}$ and $b^{\prime \prime}$ the government chooses optimally to follow the decreasing debt path converging to $b=0$. This is both feasible, as it entails positive consumption, and optimal, because $V^{-}(b)>V^{+}(b)$. When we are to the right of both $b^{\prime}$ and $b^{\prime \prime}$ it is both feasible and optimal to choose a debt path converging to $b=\bar{b}$. When we are to the right of $b^{\prime \prime}$ and to the left of $b^{\prime}$, the government optimal behavior depends on bond prices. If investors expect a decreasing debt path and select the bond schedule $Q^{-}$, the government finds it optimal to choose a $\dot{b}<0$, since $V^{-}(b)>V^{+}(b)$, and this choice is feasible. If instead investors expect an increasing debt path and select $Q^{+}$, then for the government it is no longer feasible to choose a $\dot{b}<0$ and the government has to choose an optimal path with $\dot{b}>0$. Notice that, by construction, both paths validate investors' expectations and thus constitute possible equilibria. This implies that we can choose the threshold $\hat{b}$ 

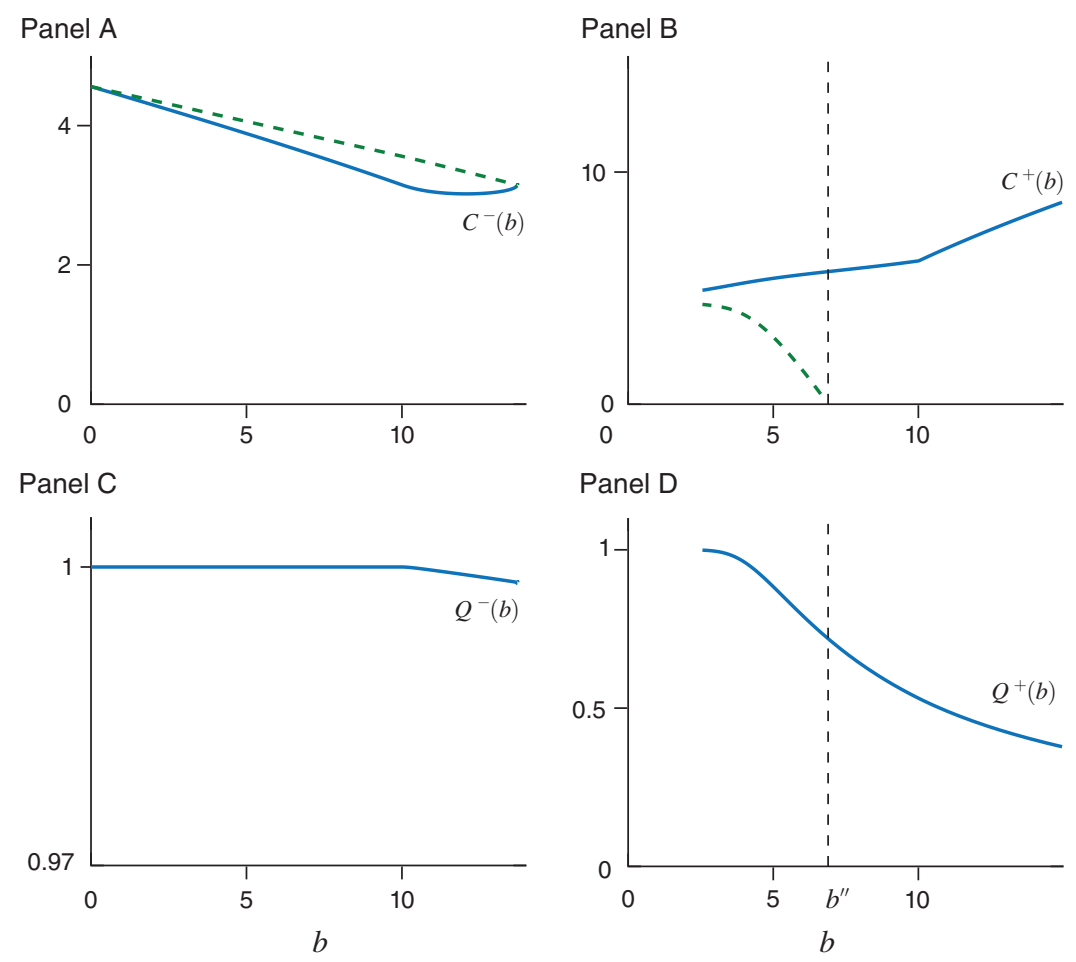

Figure 13. Consumption And Bond Price Functions

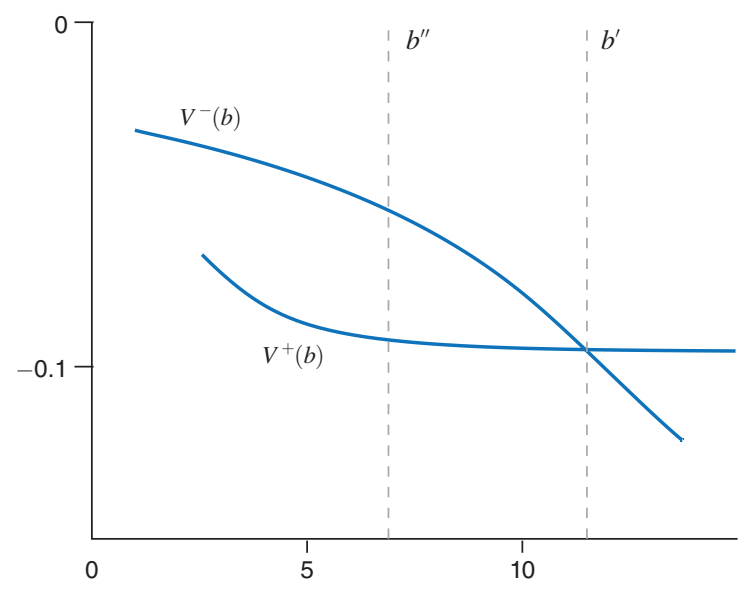

Figure 14. VAlue Functions

anywhere in the interval $\left(b^{\prime \prime}, b^{\prime}\right]$ and obtain a Markov equilibrium. Figure 14 immediately implies that these equilibria are Pareto ranked by the threshold $\hat{b}$, with the best equilibrium at $\hat{b}=b^{\prime}$.

Notice the role of the non-negativity constraint on government consumption in the construction above. If the cutoff $b^{\prime \prime}$ was to the right of the cutoff $b^{\prime}$, the equilibrium would be unique, as the government, by choosing the sign of $\dot{b}$ would always be able to choose the path that delivers the highest value. When instead 
$b^{\prime \prime}>b^{\prime}$, feasibility rules out this choice. Importantly, in our example the non-negativity constraint does not bind on the equilibrium path, but it matters off the equilibrium path. The more general point is that there are many constraints on the adjustment of government deficits that can lead to multiplicity in a similar way. Governments face a host of restrictions on the ability to change spending plans and taxes quickly. Such constraints may not bind along the equilibrium path, but they do affect deviations off the equilibrium path that set the stage for multiplicity.

\section{Microfoundations}

In previous sections, we assumed that when the government budget constraint can be satisfied at multiple bond prices, the government cannot select the most favorable price by committing to issue a certain quantity of bonds. In Section IB, we discussed informally the logic behind this timing assumption. In this section, we study a game that provides a microfoundation for it.

The game builds on the two-period model of Section IIIB, but introduces an optimizing government as in Section $\mathrm{V}$. The objective of the government is to maximize

$$
u(c)+\beta W(b)
$$

where $u(c)$ is the government utility in the first period that depends on government spending $c$, and $W(b)$ is the continuation utility that depends on the stock of bonds $b$. In particular, we assume that $W(b)$ comes from the optimal decision to repay or default in the second period, which is modeled exactly as the period in which uncertainty is resolved in Section V. Therefore, we have

$$
W(b)=\frac{1}{1-\beta} \int_{0}^{\infty} U(\max \{Y-r b, \eta Y\}) d H(Y)
$$

where $Y$ are long-run tax revenues, distributed with c.d.f. $H(Y)$, and $\eta$ is the fraction of revenues that the government keeps upon default. This is just the discrete-time analog of (18).

Bonds are modeled as long-term bonds with coupon $\kappa=r+\delta$ that decays at rate $\delta$, as in previous sections. In the first period the government receives the given tax revenue $\bar{y}$ and has an initial stock of bonds $b_{-}$inherited from the past. Therefore, the government budget constraint is

$$
c+\kappa b_{-}=\bar{y}+q\left(b-(1-\delta) b_{-}\right)
$$

The rational expectations condition for prices can be written as in (8):

$$
Q(b)=1-F(b)+\phi \int_{0}^{b} \frac{Z}{b} d F(Z),
$$

using the change of variable $Z=\frac{1-\eta}{r} Y$ as in Section $\mathrm{V}$.

We now model in detail how the government and the investors interact in the first period, determining the total amount of bonds issued. The first period is divided into infinitely many rounds indexed by $i=1,2, \ldots$, and the government 
can run an auction in each round. Think of auctions taking place in real time at $t=0,1 / 2,2 / 3,3 / 4, \ldots$. After any number of rounds, the government can choose to stop auctioning government bonds and use the funds raised to pay $\kappa b_{-}$and purchase $c$. Letting $d_{i}$ denote bond issuances in round $i$, the total stock of bonds at the end of the first period is

$$
b=(1-\delta) b_{-}+\sum_{i=0}^{\infty} d_{i}
$$

At each auction $i$ the investors bid the price $q_{i}$. We make two important assumptions: in each auction the government cannot commit to issuances in future auctions; bonds issued in different auctions are all treated equally. This model of sequential debt auctions is related to the model of sequential borrowing in Bizer and DeMarzo (1992). The main two differences are that they assume that seniority rules apply to successive debt issuances and that the main contractual friction is the presence of a moral hazard problem. In our context, it makes sense to assume that bonds issued in all auctions are treated equally, which is consistent with the pari passu clause prevalent in sovereign debt. 17

Strategies are described by functions $d_{i}=\mathcal{D}\left(d^{i-1}, q^{i-1}\right)$ and $q_{i}=\mathcal{Q}\left(d^{i}, q^{i-1}\right)$, where $d^{i}=\left(d_{0}, \ldots, d_{i}\right)$ and $q^{i}=\left(q_{0}, \ldots, q_{i}\right)$. A subgame perfect equilibrium requires that:

(i) In round $i$, after any history $\left(d^{i-1}, q^{i-1}\right)$, the government strategy is optimal at all remaining rounds $j=i, i+1, \ldots$, given that future prices satisfy $q_{j}=\mathcal{Q}\left(d^{j}, q^{j-1}\right)$ at $j=i, i+1, \ldots$.

(ii) The price in round $i$ after history $\left(d^{i}, q^{i-1}\right)$ satisfies $\mathcal{Q}\left(d^{i}, q^{i-1}\right)$ $=Q\left((1-\delta) b_{-}+\sum_{i=0}^{\infty} d_{i}\right)$ where $\left\{d_{i}\right\}$ is computed using $\mathcal{D}$ and $\mathcal{Q}$ at all future dates.

Observe that along an equilibrium path the bond price is constant in all rounds in which bonds are issued, $q_{i}=q^{*}$ if $d_{i} \neq 0$. We can then denote by $\left(b^{*}, q^{*}\right)$ an equilibrium outcome of the game in terms of total debt issued and the bond price. In the following proposition, we consider an alternative, auxiliary game in which the government chooses directly the total debt issued $b$, but takes the price $q^{*}$ as given. The proposition shows that every outcome of the auxiliary game is also an outcome of the original game described above.

PROPOSITION 9: Suppose there is a pair $\left(b^{*}, q^{*}\right)$ such that

$$
b^{*}=\underset{b}{\operatorname{argmax}} u\left(\bar{y}+q^{*}\left(b-(1-\delta) b_{-}\right)-\kappa b_{-}\right)+\beta W(b)
$$

and $q^{*}=Q\left(b^{*}\right)$. There exists a subgame perfect equilibrium of the bond auction game that yields $\left(b^{*}, q^{*}\right)$ as equilibrium outcomes.

\footnotetext{
${ }^{17}$ Previous work connecting the Bizer and DeMarzo (1992) model to the sovereign debt literature is Hatchondo and Martinez (no date). Hatchondo, Martinez, and Sosa-Padilla (2016) discuss the idea of introducing seniority covenants in sovereign debt markets.
} 
In the online Appendix, we present an example in which there are multiple pairs $\left(b^{*}, q^{*}\right)$ that solve the auxiliary game of Proposition 9. ${ }^{18}$ Using Proposition 9, we can then argue that equilibrium multiplicity survives once we introduce an optimizing government and explicitly model the process by which the government issues bonds. Notice that the argument of Proposition 9 does not depend on the specific shape of the $W$ and $Q$ functions, so it is possible to extend the argument to a full dynamic setting.

The main intuition for Proposition 9 is that the presence of future auctions limits the ability of the government to use bond issuances to avoid the bad equilibrium. Along the equilibrium path, the market faces the government with a price schedule that is flat at $q^{*}$, consistent with its expectations about the total amount of bonds that will be eventually issued, $b^{*}$. If the government deviates and issues $b<b^{*}$, the market expects the difference $b^{*}-b$ to be issued at the next auction. The assumption that a further round is always available delivers equilibria with outcomes that are equivalent to that of a price-taking government.

The idea of the argument in Proposition 9 is reminiscent of the Coase conjecture, whereby a durable goods (in our case, long-term bonds) monopolist competes intertemporally with itself and is thus reduced to competitive behavior.

\section{Conclusions}

Our formal analysis supports the idea that countries may become entrapped in self-fulfilling, slow moving debt crises. During such a crisis, interest rates rise, increasing the path for debt and raising future default probabilities. Our results also show that a sufficiently aggressive fiscal policy rule and longer debt maturities can help prevent the occurrence of slow moving debt crises.

\section{REFERENCES}

Aguiar, Mark, and Manuel Amador. 2013. "Sovereign Debt." In Handbook of International Economics, Vol. 4, edited by Gita Gopinath, Elhanan Helpman, and Kenneth Rogoff, 647-89. Amsterdam: Elsevier.

Aguiar, Mark, Manuel Amador, Emmanuel Farhi, and Gita Gopinath. 2013. "Crisis and Commitment: Inflation Credibility and the Vulnerability to Sovereign Debt Crises." Unpublished.

-Alesina, Alberto, Mark De Broeck, Alessandro Prati, Guido Tabellini, Maurice Obstfeld, and Sergio Rebelo. 1992. "Default Risk on Government Debt in OECD Countries." Economic Policy 7 (15): 427-63.

Arellano, Cristina. 2008. "Default Risk and Income Fluctuations in Emerging Economies." American Economic Review 98 (3): 690-712.

Arellano, Cristina, and Ananth Ramanarayanan. 2012. "Default and the Maturity Structure in Sovereign Bonds." Journal of Political Economy 120 (2): 187-232.

Auclert, Adrien, and Matthew Rognlie. 2014. "Unique Equilibrium in the Eaton-Gersovitz Model of Sovereign Debt." Unpublished.

Bi, Huixin. 2012. "Sovereign Default Risk Premia, Fiscal Limits, and Fiscal Policy." European Economic Review 56 (3): 389-410.

Bizer, David S., and Peter M. DeMarzo. 1992. "Sequential Banking." Journal of Political Economy $100(1): 41-61$.

\footnotetext{
${ }^{18}$ To make sure that the maximization problem in Proposition 9 is well defined, we need to assume that either $u(c)$ reaches its $\max$ at some finite value $\bar{c}$, or to impose some exogenous bound on $b$. Otherwise, since the government takes $q^{*}$ as given, the government can reach infinite utility for any $q^{*}>0$. In the example in the online Appendix we take the first route, by using a quadratic $u$.
} 
Bohn, Henning. 1995. "The Sustainability of Budget Deficits in a Stochastic Economy." Journal of Money, Credit and Banking 27 (1): 257-71.

Bohn, Henning. 2005. "The Sustainability of Fiscal Policy in the United States." In Sustainability of Public Debt, edited by Reinhard Neck and Jan-Egbert Sturm, 15-49. Cambridge, MA: MIT Press.

Calvo, Guillermo A. 1988. "Servicing the Public Debt: The Role of Expectations." American Economic Review 78 (4): 647-61.

Chamon, Marcos. 2007. “Can Debt Crises Be Self-Fulfilling?” Journal of Development Economics 82 (1): 234-44.

Cole, Harold L., and Timothy J. Kehoe. 1996. “A Self-Fulfilling Model of Mexico’s 1994-95 Debt Crisis.” Federal Reserve Bank of Minneapolis Staff Report 210.

Cole, Harold L., and Timothy J. Kehoe. 2000. "Self-Fulfilling Debt Crises." Review of Economic Studies 67 (1): 91-116.

Conesa, Juan Carlos, and Timothy J. Kehoe. 2012. "Gambling for Redemption and Self-Fulfilling Debt Crises." Federal Reserve Bank of Minneapolis Staff Report 465.

Corsetti, Giancarlo, and Luca Dedola. 2011. "Fiscal Crises, Confidence and Default: A Bare-Bones Model with Lessons for the Euro Area." Unpublished.

Corsetti, Giancarlo, and Luca Dedola. 2013. "The Mystery of the Printing Press: Self-Fulfilling Debt Crises and Monetary Sovereignty." CEPR Discussion Paper DP9358.

Eaton, Jonathan, and Mark Gersovitz. 1981. "Debt with Potential Repudiation: Theoretical and Empirical Analysis." Review of Economic Studies 48 (2): 289-309.

Frankel, David M., Stephen Morris, and Ady Pauzner. 2003. "Equilibrium Selection in Global Games with Strategic Complementarities.” Journal of Economic Theory 108 (1): 1-44.

Ghosh, Atish R., Jun I. Kim, Enrique G. Mendoza, Jonathan D. Ostry, and Mahvash S. Qureshi. 2013. "Fiscal Fatigue, Fiscal Space and Debt Sustainability in Advanced Economies." Economic Journal 123 (566): F4-F30.

Giavazzi, Francesco, and Marco Pagano. 1989. "Confidence Crises and Public Debt Management." NBER Working Paper 2926.

Greenlaw, David, James D. Hamilton, Peter Hooper, and Frederic S. Mishkin. 2013. "Crunch Time: Fiscal Crises and the Role of Monetary Policy.” NBER Working Paper 19297.

-Hall, Robert E. 2014. "Fiscal Stability of High-Debt Nations under Volatile Economic Conditions." German Economic Review 15 (1): 4-22.

Hatchondo, Juan Carlos, and Leonardo Martinez. No date. "Credit Risk without Commitment." Unpublished.

Hatchondo, Juan Carlos, and Leonardo Martinez. 2009. "Long-Duration Bonds and Sovereign Defaults." Journal of International Economics 79 (1): 117-25.

-Hatchondo, Juan Carlos, Leonardo Martinez, and César Sosa-Padilla. 2016. "Debt Dilution and Sovereign Default Risk." Journal of Political Economy 124 (5): 1383-422.

Krishnamurthy, Arvind, Stefan Nagel, and Annette Vissing-Jorgensen. 2013. "ECB Policies Involving Government Bond Purchases: Impact and Channels.” Unpublished.

-Leeper, Eric M. 1991. "Equilibria under 'Active' and 'Passive' Monetary and Fiscal Policies.” Journal of Monetary Economics 27 (1): 129-47.

Lorenzoni, Guido, and Iván Werning. 2019. "Slow Moving Debt Crises: Dataset." American Economic Review. https://doi.org/10.1257/aer.20141766.

Navarro, G., J. P. Nicolini, and P. Teles. 2014. "Sovereign Default: The Role of Expectations." Unpublished. 